\title{
SOBRE LA CULPABILIDAD EMPRESARIAL: NOTAS PARA UNA COEXISTENCIA EFICAZ DE LOS ARTÍCULOS 31BIS Y 129 DEL CÓDIGO PENAL
}

\author{
Sergio Pérez González ${ }^{1}$
}

Resumen: El artículo propone valorar la dimensión culpable de las empresas a partir de la implementación de protocolos de cumplimiento. Así, las empresas con un compliance eficaz a priori podrían ser inimputables, pero eso no evitaría la persistencia de su peligrosidad. Esta circunstancia podría atenderse mediante una reformulación del art. 129 $\mathrm{CP}$, que así podría dotarse de racionalidad pragmática y sistemática, compatibilizándose con el art. 31bis CP.

Palabras clave: Empresas, compliance, culpabilidad, inimputabilidad, peligrosidad.

Recibido: julio 2019. Aceptado: noviembre 2019

1 Profesor contratado de Derecho penal. Orcid ID 0000-0002-9029-7180

Departamento de Derecho. Facultad de Ciencias Jurídicas y Sociales de la Universidad de La Rioja. Dirección C/ La Cigüeña, 60, Logroño. E-mail: sergio.perezg@unirioja.es 


\begin{abstract}
This work proposes to assess the corporate culpability based on the implementation of compliance programs. Thus, companies with effective compliance could not be imputable and, despite that, they still can be dangerous. This dimension could be addressed through a reformulation of art. $129 \mathrm{CP}$. This would attend to the pragmatic and systematic rationality and tries compatibility with art. 31 bis $\mathrm{CP}$.
\end{abstract}

Keywords: Companies, compliance, culpability, imputability, danger.

\title{
Introducción
}

Las notas que siguen surgen desde una preocupación concreta. La posibilidad de que, tras la introducción en 2015 de la causa de exención de responsabilidad por la implantación de programas de cumplimiento, algunas personas jurídicas queden -bajo cierta sistematicidad-al margen de toda consecuencia penal, independientemente del daño social causado por razón de su actuación.

Esta preocupación se hace objeto de análisis cuando notamos que el derecho penal da un trato muy diferenciado a realidades parangonables protagonizadas por personas físicas. Y es que, en estos casos, el sistema penal, históricamente, ha buscado soluciones para actuar ante el daño causado, aun no siendo este imputable a una persona concreta. En el ámbito de las personas jurídicas, sin embargo, el legislador parece atrapado entre las persistencias dogmáticas y sus excepciones, entre las penas sui generis y las consecuencias accesorias, entre la prevención y la retribución contenida...

Las hipotéticas soluciones a este desajuste condicionan, entonces, la hermenéutica de nuestro estudio - esto es, la interpretación del texto legal-. Así, la ascensión desde la literalidad normativa a las categorías dogmáticas debe comprenderse, en las páginas siguientes, funcionalizada en atención al fin marcado por aquella preocupación criminológica. 
Desde 2010 -antes también, a partir de prospecciones en las legislaciones del entorno $y$, de manera modulada, desde 2015- la doctrina española ha valorado muy distintamente la naturaleza dogmática de la responsabilidad penal de las personas jurídicas. No pretendemos, sin embargo, adscribirnos a una línea dogmática por principio, ya que, a nuestro juicio, esto no debe ser, necesariamente, un punto de partida estable para todas las deducciones prácticas posteriores. Con el objetivo de dar solución a la preocupación anunciada, pretendemos inducir desde el texto legal una categorización dogmática determinada que pueda ser resolutiva: en concreto, asumiremos motivadamente la culpabilidad empresarial como terreno de juego lógico y funcional en el que interpretar y reformular la cohabitación de los artículos 31 bis y 129 del Código penal.

El entuerto anunciado, entonces, podría concretarse y, a la vez, tornarse resoluble si constatamos una premisa esencial: que, efectivamente, la letra del art.31bis $\mathrm{CP}$-en concreto, la previsión de exención a través de protocolos de prevención del delito eficaces- nos llevase a categorizar a determinadas empresas como inimputables a priori, sin ulteriores consecuencias jurídico-penales aun en casos de graves daños a bienes jurídicos esenciales. En este trabajo, por tanto, pretendemos valorar la recepción y posibilidades de ajuste dogmático de este problema a través de los artículos 31 bis y 129 del Código penal.

De este modo, posicionados con cierta solidez en el territorio dogmático, parecería necesaria una adaptación normativa de calado si pudiese constatarse que, efectivamente, la implantación de los protocolos de cumplimiento determina la ausencia de culpabilidad de las personas jurídicas en relación con un hecho típico, pero no la ausencia de peligrosidad. Esto es, si desde una perspectiva político-criminal puede constatarse que la implantación de los programas de cumplimiento no evita la consecución de hechos típicos y antijurídicos desde las empresas (vale decir, si los programas de cumplimiento no fueran eficaces a posterio$r i$ en relación con el hecho concreto), entonces el legislador esta- 
ría obligado a atender la interpretación dogmática esbozada, esto es, debería atender a la peligrosidad empresarial de un modo más certero que como lo hace actualmente. Y esto de manera independiente a la proyección de la eficacia del compliance a priori. Las líneas que siguen pretenden ofrecer algunas notas para atender esta cuestión.

\section{Proceso inductivo hacia una naturaleza dogmática del compliance}

A partir de la literalidad legal, esto es, de las previsiones típicas contenidas en el $\mathrm{CP}^{2}$, pretendemos valorar las líneas doctrinales que han fundamentado dogmáticamente el artefacto jurídico del compliance ${ }^{3}$, aunque orientados, en último término, por el fin criminológico expuesto ${ }^{4}$.

2 En concreto, en el 31 bis. 1 a) (por sus representantes legales o por aquellos que [...] están autorizados para tomar decisiones en nombre de la persona jurídica u ostentan facultades de organización y control dentro de la misma), en relación con el 31bis.2 (modelos de organización y gestión que incluyen las medidas de vigilancia y control); asimismo, en el art. 31bis.1 b) (por quienes, estando sometidos a la autoridad de las personas físicas mencionadas en el párrafo anterior), en relación con el 31 bis. 4 (modelo de organización y gestión que resulte adecuado para prevenir delitos de la naturaleza del que fue cometido).

3 Sobre esta cuestión, hay abundante literatura. La bibliografía seleccionada no es exhaustiva, pero sí pretende dibujar una panorámica en la que poder situar aproximativamente nuestro desarrollo teórico concreto.

4 Esta postura pragmática es, en último término, la que marca el sentido de la regulación en este ámbito. Como señala ZUGALDÍA ESPINAR, "los legisladores han hecho caso omiso del histórico e intenso debate académico sobre la capacidad de acción y de culpabilidad de las personas jurídicas (...) por razones de necesidad y puramente pragmáticas (...) fundamentalmente para combatir la criminalidad económica organizada" (ZUGALDÍA ESPINAR, J.M. "Societas delinquere potest: análisis de la reforma operada en el Código Penal español por la LO 5/2010, de 22 de junio", La ley penal: revista de derecho penal, procesal y penitenciario, n. 76, 2010, p.1). Véase también ZUGALDÍA ESPINAR, J.M., La responsabilidad criminal de las personas jurídicas, de los entes sin personalidad y de sus directivos: (análisis de los arts. 31 bis y 129 del Código Penal), Valencia, 2013, pp. 20 y ss. 
Esta labor, inevitablemente, implica posicionar en el plano dogmático el itinerario de imputación de las personas jurídicas en nuestro sistema penal. En un principio, del texto de 2010 parecía desprenderse que la responsabilidad penal de la empresa era vicarial, esto es, se derivaba de un hecho ajeno cometido por una persona física que, en su interior $-\mathrm{y}$ según las vías de atribución descritas en el art. 31 bis $\mathrm{CP}-$, obraba en provecho de la persona jurídica. Las diatribas llegaban, entonces, a propósito de la ilegitimidad de un castigo fundamentado en el hecho ajeno $^{5}$, generando una suerte de responsabilidad objetiva para la empresa ${ }^{6}$.

Estas posiciones doctrinales se derivaban, primariamente, de una concepción restrictiva -humanista, digamos- del sujeto como tal, que condicionaba así la concepción del sujeto activo como elemento típico penal ${ }^{7}$. Por ello, la primera parada en esta disección de elementos hacia su ajuste dogmático pasa por caracterizar la empresa como sujeto y, en ello, como sujeto activo. Es necesario, por tanto, fijar una ontología de la empresa que sirva de fundamento para su relación funcional con el entorno, señaladamente con la norma penal.

5 El sistema de responsabilidad penal de las personas jurídicas no puede considerarse vicarial, sino que exige "la infracción culpable de deberes que le competen precisamente a ella" (ZUGALDÍA ESPINAR, J.M. "Societas delinquere potest...", cit., p.2).

6 Antes de la reforma de 2015, HERNÁNDEZ DÍAZ remitía la solución de estos conflictos dogmáticos a la práctica judicial, ya que las especulaciones doctrinales recorrían campos muy abiertos ("El nuevo artículo 31 bis del Código penal: exigencias legales (explícitas e implícitas) que permiten la atribución de responsabilidad penal a la persona jurídica", en DE LA CUESTA ARZAMENDI, J.L. (dir.) y DE LA MATA BARRANCO, N.J. (coord.), Responsabilidad Penal de las Personas Jurídicas, Cizur Menor, 2013, p. 120).

7 "El cuestionamiento que se ha hecho en este contexto en relación con los conceptos de acción y culpabilidad (...) se encuentra directamente vinculado al cuestionamiento de la noción del sujeto mismo" (BACIGALUPO SAGESSE, S.: "Los criterios de imputación de la responsabilidad penal de los entes colectivos y de sus órganos de gobierno (arts. 31 bis y $129 \mathrm{CP}$ )", en Diario La Ley, $\mathrm{n}^{\circ} 7541,2011$, p. 2). 


\subsection{La empresa como sujeto}

La ontología hegemónica de la persona en derecho penal parte, sin duda, de cierta tradición idealista. La persona es concebida como unidad primigenia, ideal, que, en sí, atesora una serie de facultades autoevidentes y que marcan una posición innegociable ab initio: la persona como una dialéctica de cuerpo y mente que actúa con libertad desde la moral y que, por tanto, es susceptible de protección y enjuiciamiento ético ${ }^{8}$.

La teoría del delito, como utensilio más depurado de la dogmática penal, emerge sobre estos presupuestos $\mathrm{y}$, en esas claves conceptuales, irrumpe la persona colectiva como elemento extraño. Indica SILVA SÁNCHEZ que, desde el idealismo alemán, "este modelo obliga a analizar la posibilidad de que concurran en la actividad de las personas jurídicas los elementos de las categorías de la clásica teoría del delito, que constituyen los presupuestos de la imposición de la pena "clásica»". Pasar a la persona jurídica por este tamiz, sin embargo, no ofrece, en principio, resultados demasiado útiles.

Sucede, por tanto, que en esta tesitura no solo debe forzarse el concepto de persona jurídica, sino que también el tamiz puede flexibilizarse en parte, de modo que la apelación al "idealismo alemán" no debe agotar la capacidad de contorsión de nuestra dogmática, y aun de la teoría del delito. Cabe apelar, entonces, a otras epistemologías para modular la dogmática y, así, adaptarla a los fines perseguidos ${ }^{10}$. La cuestión, entonces, consiste en dilu-

8 Sobre esta idea se gesta la noción de bien jurídico personalista, así como un sistema de imputabilidad que presupone conciencia y libertad. Véase PÉREZ GONZÁLEZ, S.: "El bien jurídico penal desde una justificación ética”, en Revista General de Derecho penal, n 31, 2019, pp. 1 y ss.

9 SILVA SÁNCHEZ, J.M.: "La evolución ideológica de la discusión sobre la responsabilidad penal de las personas jurídicas", en Revista de Derecho penal y criminología, 29, núm. 86-87, 2008, p. 136.

10 En este juego de adaptación de la dogmática se persigue el objetivo que, según ATIENZA, pasaría por permanecer en un ámbito de previsibilidad comunicativa (un conjunto de nociones comunes), pero moduladas en atención a un fin práctico, esto es, la dogmática como tecno-praxis: "La dogmática jurídica no sería exactamente una rama de la filosofía práctica, sino más 
cidar si cabe una noción de la persona jurídica, del ente colectivo o de la empresa, por ser más concretos, que, sin arrastrar el idealismo de la persona física, sea operativa en la teoría del delito. Se trata, entonces, de ensayar una ontología de la empresa.

La definición jurídica de la empresa es, precisamente, la que de manera más certera puede darle este vuelo funcional. Decía WEBER que el capitalismo existía antes de la forma jurídica asalariada, sin embargo, el sociólogo alemán localizaba en esta forma jurídica $-\mathrm{y}$ en la organización empresarial erigida sobre el trabajo formalmente libre ${ }^{11}$ - la verdadera transformación que diferencia a la economía como estructura hegemónica bajo el formato del "capitalismo empresarial burgués"12. La característica principal de la empresa sería, entonces, jurídica, ya que sobre esa característica concreta pivota toda una reformulación de las relaciones económicas y sociales. La empresa se propone desde el derecho como un sujeto que, en su interior, regula funcional y geográficamente personas físicas, y que ostenta un patrimonio propio, gestionado, a su vez, por personas físicas pero separado de ellas. Así, indica CARBONELL MATEU que "no debe olvidarse que una de las funciones básicas que desempeñan las sociedades - puede decirse, en realidad, que, al menos en buena parte, para eso se inventaron- es la de limitar la responsabilidad individual de las personas físicas. La cuestión es meridianamente clara en el ámbito de la responsabilidad patrimonial"13.

bien un híbrido entre técnica (...) social y filosofía práctica” (ATIENZA RODRÍGUEZ, M.; "La dogmática jurídica como tecno-praxis", en CARBONELL SÁNCHEZ, M., FIX FIERRO, H. y VALADÉS, D., Estado constitucional, derechos humanos, justicia y vida universitaria. Estudios en homenaje a Jorge Carpizo, tomo IV, México, 2015, p. 196).

11 "Occidente conoce en la Edad Moderna una forma de capitalismo completamente distinta y que no se ha desarrollado en ningún otro lugar de la tierra: la organización racional-capitalista del trabajo (formalmente) libre. En otros lugares sólo se encuentran niveles previos de este capitalismo" (WEBER, M.: La ética protestante y el espíritu del capitalismo, trad. J. Pérez, Madrid, (1905) 2015, pp. 82-83).

12 WEBER, M.: La ética protestante... cit. p. 85.

13 CARBONELL MATEU, J.C.: "Responsabilidad penal de las personas jurídicas. Reflexiones en torno a su «dogmática» y al sistema de la reforma de 
El asunto es, entonces, si en el ámbito penal debe atenderse a esta naturaleza de la empresa que conforma, precisamente, un actuar autónomo de los condicionamientos materiales de las personas físicas (el riesgo sobre el propio patrimonio) ${ }^{14}$. Esto es, la empresa actúa en la manera en que lo hace, justamente, porque, por definición jurídica, no es la suma de los sujetos físicos que la participan. Es, a la inversa, un ente que solo pretende ser para no ser la suma de los sujetos físicos que lo integran. Comprendemos la empresa, entonces, como un complejo estructural atributivo que desborda la suma de sus componentes (personas físicas). Vale decir, entendemos la empresa como un constructo jurídico que toma decisiones en un nivel distinto del de las personas físicas que la componen, más allá de que, como sujeto, no goce de capacidad reflexiva o conciencia de sí misma ${ }^{15}$. En ello radicó su éxito económico como programación jurídica.

2010", en Cuadernos de política criminal, $\mathrm{N}^{\circ}$ 101, 2010, pp. 4-5. La prueba de validez histórica sobre esta característica de la empresa como esencia de la misma podemos localizarla en la experiencia de la Ley de la burbuja inglesa, a propósito de la crisis económica sucedida tras la caída de las acciones de la Compañía de los Mares del Sur. El Parlamento inglés aprobó en 1720 la Bubble Act, mediante la que pretendía evitar la creación de negocios vacíos (burbujas) surgidos de la ligereza con que se firman contratos si el patrimonio individual no está en juego. Este condicionante de la organización empresarial (esta responsabilidad patrimonial personal) no pudo sostenerse entrado el siglo XIX, ya que se demostraría poco competitivo en relación con otras regulaciones. En la responsabilidad personal limitada radicaba la operatividad de la empresa. Véase, sobre este asunto, HARRIS, R.: "The Bubble Act: Its Passage and Its Effects on Business Organization", en The Journal of Economic History, vol. 54, n³, 1994, pp. 610-627

14 Así, CARBOnELl MATEU, J.C.: "Responsabilidad penal...", cit., p.5: "Lo que ahora debemos plantearnos es la conveniencia político criminal de que dicha función de limitar la responsabilidad patrimonial de las personas físicas deba o no extenderse a la penal".

15 Y sirven aquí las nociones básicas del estructuralismo jurídico en HERNÁNDEZ GIL, A.: "Introducción al estudio del estructuralismo y el derecho", en HERNÁNDEZ GIL, A., NÚÑEZ LADEVÉZE, L., SOBRADO CHAVES, J.J. [et al.], Estructuralismo y Derecho, Madrid, 1973, p. 27: “Lo irreflexivo, esto es, lo no alcanzado en virtud de una actuación consciente, encierra regularidades, implicaciones y equivalencias que constituyen la trama de la estructura". La empresa, entonces, encierra esas regularidades al margen de las voluntades concretas de las personas físicas. 
La situación jurídica, económica y social de la empresa la coloca, entonces, en unos parámetros de comunicación y expectativas propios que condicionan su actuar como sujeto social autónomo de las personas físicas. Esto debe ser recogido por el sistema penal, sin perjuicio de que siga existiendo otra recepción, en paralelo, para el actuar de las personas físicas que recorren la empresa.

Esta ontología estructuralista de la empresa encaja, en lo esencial, con las nociones constructivistas que propone GÓMEZ-JARA a partir de los presupuestos sociológicos luhmannianos ${ }^{16}$. Lo cierto es que estas concepciones han traído consecuencias prácticas un tanto perturbadoras en relación con el tratamiento penal de las personas físicas ${ }^{17}$, sin embargo, precisamente en el contexto de las personas jurídicas, esta articulación conceptual puede sacudirse las objeciones clásicas que desde posiciones garantistas se han hecho al funcionalismo.

Si tuviéramos que definir a la persona física, podríamos hacerlo desde muchas disciplinas (la biología, la química, la religión...). También podríamos hacerlo desde el derecho, como propone JAKOBS, a través del concepto ciudadanía ${ }^{18}$. Y cada definición sería más o menos funcional según los objetivos per-

16 GÓMEZ-JARA DÍEZ, C.: "La culpabilidad de la persona jurídica", en BAJO FERNÁNDEZ, M., FEIJOO SÁNCHEZ, B.J. y GÓMEZ-JARA DÍEZ, C., Tratado de responsabilidad penal de las personas jurídicas: adaptado a la Ley 1/2015, de 30 de marzo, por la que se modifica el Código Penal, Cizur Menor, 2016, p. 170: "Una teoría coherente de cómo el sistema jurídico (Derecho), el sistema organizativo (persona jurídica) y el sistema psicofísico (individuo) gozan, en determinadas circunstancias, de una autorreferencialidad propia".

17 Como nota GÓMEZ-JARA ("La culpabilidad...”, cit., p. 171), la autorreferencialidad de la persona jurídica como tal suscita muchas dudas en la ciencia penal.

18 JAKOBS señala que las personas -a diferencia de los individuos (que son indivisibles según su etimología)- serían "destinos construidos comunicacionalmente", de tal modo que el derecho penal ya no observaría al sujeto según cierta esencia de lo humano, sino según las normas determinantes de su comunicación (JAKOBS, G.: Sobre la normativización de la dogmática jurídico-penal, trad. Manuel Cancio Meliá y Bernardo Feijóo Sánchez, Madrid, 2003, pp. 17-18). En concreto, esta sería una comunicación codificada 
seguidos. Por otro lado, si tuviéramos que definir a la persona jurídica, como hemos notado, la definición más funcional para el objetivo planteado pasaría por considerar, justamente, su dimensión jurídica. Y esto es así porque, a diferencia de lo que sucede con las personas físicas, solo desde la definición jurídica de la empresa cabe interponer, como trataremos de exponer, un juicio de reproche ético.

De este modo, cabe concebir el hacer empresarial en sus propios esquemas de acción debida, sin dependencia de los esquemas correlativos de los individuos que transitan la empresa. Así, no solo la empresa no es el resultado aditivo de personas físicas, sino que los parámetros de decisión no dependen de las psicologías de las personas físicas que operan en su interior. La normativa empresarial (el derecho que la condiciona, pero también sus propias normas internas), conforman el circuito neuronal de la persona jurídica, esto es, su programación compleja ${ }^{19}$.

El hacer de las personas físicas que actúan en el interior de la empresa, por tanto, debe considerarse más condicionado por aquella programación empresarial que a la inversa. Esto es, la programación empresarial no depende de los procesos volitivos singulares de personas físicas, sino que, fundamentalmente, se tejen en dinámicas económicas y jurídicas que trascienden las voluntades de las personas físicas que hacen las empresas ${ }^{20}$.

jurídicamente, ya que el enemigo, para Jakobs, lo marca un statu iniusto (JAKOBS, G. Y CANCIO MELIÀ, M., Derecho penal del enemigo, trad. M. Cancio Melià, Cizur Menor, 2006, p. 41). Véase también JAKOBS, G.: Sociedad, norma y persona en una teoría de un Derecho penal funcional, trad. M. Cancio Meliá y B. Feijóo Sánchez, Madrid, 2000

19 Resulta muy ilustrativo transportar a nuestro objeto de estudio -desde el plano de regulaciones mediante la programación- las argumentaciones de LESSIG (Code 2.0, New York, 2006): el derecho puede condicionar el actuar humano sin interpelar directamente a la conciencia humana, sino condicionando su campo de actuación. La empresa, como forma jurídica dispositiva, es un ejemplo palmario de esta relación normativa entre programación jurídica y acción individual.

20 "La persona jurídica tiene una capacidad de organización que debe servir al mismo propósito, debiendo asumirse que las personas jurídicas tienen capa- 
La sublimación de esta lógica se produce con las decisiones empresariales ejecutadas automáticamente por programaciones algorítmicas, práctica cada vez más común en las grandes corporaciones (o no tan grandes).

No habría, por tanto, responsabilidad objetiva en el reproche penal. La responsabilidad subjetiva de la persona jurídica puede ser concebida en lógicas de actuación de personas físicas -de un modo figurativo- lo que no significa que la volición de las personas físicas determine la de la persona jurídica, sino que, inversamente, son las rutinas empresariales las que instrumentalizan personas físicas (no necesariamente en el sentido jurídico penal que nos llevaría a verificar autorías mediatas). Por tanto, sucede una vehiculización de la subjetividad de la empresa en esos haceres humanos, sin que en ello se difumine tal responsabilidad subjetiva de la persona colectiva.

\subsection{Hecho propio de la empresa}

El segundo momento de nuestra disección pasa por identificar el hecho típico que genera la responsabilidad empresarial $^{21}$. Esto siempre es una tarea epistemológicamente vacilante

cidad de organizar las acciones de las personas físicas o que tienen capacidad para organizar los contactos sociales de las personas físicas, conforme a derecho (...) La teoría de la organización destaca la existencia de una estructura de relaciones de interdependencia entre las partes de la organización que permiten considerar a las empresas como un todo, cuya desestructuración afecta a ámbitos protegidos del derecho" (PÉREZ MACHÍO, A.I.: La responsabilidad penal de las personas jurídicas, Granada, 2017, p. 67).

21 Una explicación panorámica y ejemplificada sobre la responsabilidad penal de las personas jurídicas se ofrece en DE LA MATA BARRANCO, N.J., DOPICO GÓMEZ-ALLER, J., LASCURAIN SÁNCHEZ, J.A. y NIETO MARTÍN, A., Derecho penal económico y de la empresa, Madrid, 2018, pp. 129 y ss. Una descripción clara entre "modelo de atribución de responsabilidad o de heterorresponsabilidad", por un lado, y "modelo de responsabilidad directa por el hecho propio (autorresponsabilidad)", por otro lado, la ofrece PÉREZ MACHÍO (La responsabilidad penal... cit., p. 73). En concreto, ZUGALDÍA ESPINAR distingue, entre los modelos de heterorresponsabilidad, el de "sistema vicarial" y el basado en "la teoría de la distribución de costes", en una suerte de "responsabilidad objetiva por el peligro"; por otro lado, el mismo autor apunta cuatro modelos de autorresponsabilidad 
ya que, al cabo, tal constatación será tendenciosa, en la medida en que ello va a estar condicionado por los fines que pretendemos alcanzar. Así, si nos interesa señalar una legitimidad de la pena aplicable a la empresa (esta es la condición del texto legal), debemos afanarnos por caracterizar el hecho cometido por la persona jurídica como hecho propio $^{22}$. De lo contrario, estaríamos avalando una suerte de responsabilidad objetiva por hechos ajenos.

En este sentido, las teorías de la atribución o de transferencia de la responsabilidad ${ }^{23}$ no parecen poder adecuarse a

empresarial: la teoría del dominio de la organización funcional sistemática, la teoría de los sistemas sociales autopoiéticos, la teoría de la acción comunicativa y el modelo del "hecho de conexión" (ZUGALDÍA ESPINAR, J.M.: "Teorías jurídicas del delito de las personas jurídicas (aportaciones doctrinales y jurisprudenciales). Especial consideración de la teoría del hecho de conexión)", Cuadernos de Politica Criminal, n. 121, I, 2017, pp. 15 y ss.). Este último sería, para ZUGALDÍA ESPINAR, el que recoge (o al que mejor se adapta) nuestro Código penal. Sobre los modelos de responsabilidad criminal, tanto indirecta o de heterorresponsabilidad, como directa o de autorresponsabilidad, puede verse también, del mismo autor, "Modelos dogmáticos para exigir responsabilidad criminal a las personas jurídicas (a propósito de las SSTS de 2 de septiembre de 2015, 29 de febrero de 2016 y 16 de marzo de 2016)", La ley penal: revista de derecho penal, procesal y penitenciario, n. 119, 2016.

22 ZUGALDÍA ESPINAR fue uno de los primeros autores españoles que reconoció el hecho empresarial como hecho propio, abogando tempranamente por un modelo de responsabilidad autónomo [ZUGALDÍA ESPINAR, J.M.: "La responsabilidad criminal de las personas jurídicas en el derecho penal español (Requisitos sustantivos y procesales para la imposición de las penas previstas en el art. 129 del Código Penal), en El nuevo Derecho Penal español. Estudios Penales en Memoria del Profesor José Manuel Valle Muñiz, coord. G. Quintero Olivares y F. Morales Prats, Aranzadi, Cizur Menor, 2001, p. 902]. GÓMEZ TOMILLO también avala esta perspectiva desde la toma sentido en clave de prevención general positiva ("Los distintos modelos de imputación de responsabilidad a las personas jurídicas: sistema español. Antecedentes", en Responsabilidad penal y procesal de las personas jurídicas, Memento experto, Madrid, 2015, p. 45). GÓMEZ-JARA indica, a propósito de la previsión del código en su art. 31bis.3 CP, que "los comportamientos de personas físicas sólo pueden considerarse como presupuestos de la responsabilidad de las personas jurídicas, pero no como su fundamento" ("La culpabilidad...", cit., p. 112).

23 SILVA SÁNCHEZ (“La evolución ideológica...”, cit., pp. 130-132) señala precedentes teóricos para esta opción en la identification doctrine anglo- 
los fundamentos básicos de imputación de nuestra dogmática penal. Sin embargo, indica SILVA SÁNCHEZ que, si abogamos por la teoría del hecho propio ${ }^{24}$, "no resulta fácil singularizar los elementos de tal hecho" 25 , ya que "en la persona jurídica no se dan los mínimos para afirmar la presencia de una acción" ${ }^{26}$. No habría siquiera volición y, por tanto, no podría cometer un hecho propio en los términos combinados de una acción y, si acaso, un resultado lesivo ${ }^{27}$. Por ello, cabe argumentar que el hecho de la persona física es atribuido a la persona jurídica.

El compliance, en esta lógica atributiva, sería un modo de evitar el contagio, esto es, un modo de salvaguardar a la persona jurídica de las acciones antijurídicas cometidas por otros, sin que por ello cambiase la naturaleza de la responsabilidad -objetiva- de la empresa por aquellos casos que quedasen al margen de la prevención del compliance, esto es, por hechos ajenos $^{28}$.

sajona. Las dudas serían, entonces, si debemos concebir dos hechos distintos (del individuo y del colectivo) para, a continuación, acomunar la pluralidad de hechos en una suerte de coautoría; o si, por el contrario, deberíamos individualizar un hecho omisivo de la persona jurídica (la vigilancia debida) que serviría de conexión con el hecho delictivo de la persona física. Véase también SILVA SÁNCHEZ, J.M.: "La evolución ideológica...", cit., p.135.

24 Véase SILVA SÁNCHEZ, J.M.: "La evolución ideológica...", cit., pp. 133-135.

25 SILVA SÁNCHEZ, J.M.: "La evolución ideológica...”, cit., p. 134.

26 SILVA SÁNCHEZ, J.M.: "La evolución ideológica...", cit., p. 139-140.

27 También cabe considerar la concurrencia de la imputación objetiva (GÓMEZ-JARA DÍEZ, C.: "La culpabilidad...", cit., pp. 126 y ss.). PÉREZ MACHÍO (La responsabilidad penal ... cit., p. 74) indica que tal imputación faltaría cuando "falte el nexo de antijuridicidad entre el defecto de organización y la producción del resultado de lesión o de peligro". Asimismo, cabe analizar la concurrencia de la tipicidad subjetiva (GÓMEZ-JARA DÍEZ, C.: "La culpabilidad...", cit., pp. 134 y ss.).

28 DE LA MATA BARRANCO ("La exclusión de la responsabilidad penal de las personas jurídicas. Protocolos de prevención de delitos", en Responsabilidad penal y procesal de las personas jurídicas, Memento experto, Madrid, 2015 , p. 100) observa que "en nuestro moderno, preventivo y motivador Derecho penal (...) no cabe una responsabilidad objetiva, menos aún por hechos ajenos". En un sentido similar, FEIJOO SÁNCHEZ ("Las características básicas de la responsabilidad penal de las personas jurídicas en el Código penal español", en BAJO FERNÁNDEZ, M., FEIJOO SÁNCHEZ, 
Además de esta difícil adecuación a los principios básicos de la dogmática penal, caben otros argumentos para recelar de las teorías de la atribución: de la ontología de la empresa propuesta, puede colegirse que, necesariamente, apostamos por una concepción del hecho delictivo como propio de la empresa, ya que la persona jurídica es una estructura autónoma que toma decisiones independientemente de la voluntad de los individuos y, por esta razón, sería más acertado engranar el texto de la ley en las pretensiones de unidad sistemática e interpretativa del sistema penal que tomen en cuenta la legitimidad de considerar tal sujeto activo ${ }^{29}$.

Así, como nota PÉREZ MACHÍO, "La irrupción de un concepto social de acción o concepción significativa de la acción favorece y permite ampliar el círculo de sujetos imputables penalmente, no limitados a las personas físicas" ${ }^{\text {30 }}$. Por tanto,

B.J. y GÓMEZ-JARA DÍEZ, C., Tratado de responsabilidad penal de las personas jurídicas: adaptado a la Ley 1/2015, de 30 de marzo, por la que se modifica el Código Penal, Cizur Menor, 2016, p. 68). Sobre estas dualidades entre hecho propio y hecho ajeno, puede consultarse también JUANES PECES, A.: "Introducción a la responsabilidad penal de las personas jurídicas. Consideraciones generales y problemas sustantivos y procesales que dicha responsabilidad suscita", en Responsabilidad penal y procesal de las personas jurídicas, Memento experto, Madrid, 2015, pp. 8 y ss. FERNÁNDEZ TERUELO concluye, sin embargo, que "el modelo adoptado tiene como principal característica la elección de una fórmula de responsabilidad de los entes sociales, parcialmente basada en la teoría de la representación (responsabilidad de la persona jurídica, que se sustenta en hechos de las personas físicas que de algún modo la representan)" ("Regulación vigente: exigencias legales que permiten la atribución de responsabilidad penal a la persona jurídica y estructura de imputación: art.31 bis 1, art.31 ter y art.31 quinquies", en Responsabilidad penal y procesal de las personas jurídicas, Memento experto, Madrid, 2015, p pp. 67 y ss.).

29 Estas especulaciones quedan avaladas por las últimas decisiones judiciales: así, por ejemplo, el Auto de 18 de abril de 2018 del Juzgado Central de Instrucción $\mathrm{n}^{\circ} 2$ de Madrid indica, sobre un procedimiento contra Caixabank, que la responsabilidad penal no es objetiva, sino que exige comprobar una actuación irregular de la empresa.

30 PÉREZ MACHÍO, A.I., Responsabilidad penal..., cit., p. 65. En el mismo sentido, "la construcción del modelo de responsabilidad penal de las personas jurídicas debe alejarse de postulados formales que, desde la perspectiva 
explica DE LA MATA BARRANCO, "no cabe una responsabilidad objetiva" 31 , "partiendo, claro está, de la capacidad de autodeterminación de la persona jurídica"32. Pero, también desde presupuestos funcionalistas, la legitimidad del sujeto activo parece evidente en las hipótesis de GOMEZ-JARA, que refiere una suerte de "hecho global" como propio, derivado de la complejidad organizativa de la empresa ${ }^{33}$.

$\mathrm{Y}$ en esta clave de hecho propio de la empresa, por tanto, la siguiente concreción relevante pasaría por señalar el hecho mismo que debe imputarse al ente colectivo como tal. GÓMEZ TOMILLO indica, a este propósito, que “(...) se requiere no solo la acción u omisión de una persona física, sino también que aquéllas aparezcan externamente como un hecho de empresa, indisolublemente asociado a la persona jurídica, que no tenga sentido desde otra perspectiva (...) Que la acción u omisión desplegada por un sujeto físico sean para un espectador objetivo una expresión de la actividad de la persona jurídica y no una conducta individual" ${ }^{34}$. Parece encajar en esta lógica la interpre-

de la acción se asocian al comportamiento humano y al paradigma psicológico e intelectivo" (PÉREZ MACHÍO, A.I., Responsabilidad penal..., cit., p. 66). Véase también "Hecho propio típico de la persona jurídica" en PÉREZ MACHÍO, A.I., Responsabilidad penal..., cit., p. 74-75.

31 DE LA MATA BARRANCO, N.J.: "Los protocolos de prevención de delitos en el ámbito empresarial: el referente de los modelos de organización y gestión de la regulación italiana", en PUENTE ABA, L.M. (ed.), Economía y Derecho penal en Europa: una comparación entre las experiencias italiana y española. Actas del Congreso hispano-italiano de Derecho penal económico. Universitá degli Studi di Milano, 29-30 de mayo de 2014, A Coruña, 2015, p. 291.

32 DE LA MATA BARRANCO, N.J.: "Los protocolos...", cit., p. 274.

33 "Desde la interpretación que aquí se propone, esta teoría permite explicar cómo la configuración -por parte de la persona jurídica- del marco organizativo en el cual la persona física ejecuta el hecho delictivo constituye el fundamento de la punición de aquélla, así como que se le pueda imputar como suyo una suerte de "hecho global" (GÓMEZ-JARA DÍEZ, C.: "La culpabilidad...", cit., pp. 269). Véase también, sobre la noción de "hecho propio", GÓMEZ-JARA DÍEZ, C.: "La culpabilidad...", cit., pp. 111 y ss.

34 GÓMEZ TOMILLO, M.: "Los distintos modelos de imputación de responsabilidad a las personas jurídicas: sistema español. Antecedentes”, en Res- 
tación de DE LA MATA BARRANCO, quien considera que el compliance señala un hecho propio vinculado al protocolo de prevención. Dice el autor: "A esto debe limitarse la posibilidad de exigir responsabilidad a la Empresa: a que no haya sido diligente en la adopción y seguimiento de ese 'correcto y completo, normativamente hablando' Protocolo" ${ }^{35}$.

Sin embargo, en esta misma senda, cabría hacer una apreciación más puntillosa sobre el hecho propio que modularía su alcance. $\mathrm{Y}$ es que el hecho atribuible directamente a la persona jurídica podría ser el que, fenomenológicamente, realiza la persona física. Esto es, la persona física activa un procedimiento, una práctica, pero tan condicionado por el entramado empresarial que ese sería el "hecho global" de la empresa. Como dice DE LA MATA, los principios básicos del derecho penal "exigen (...) una actuación ilícita 'propia' y no una responsabilidad derivada 'sólo' de hechos ajenos"36. Pero quizá cabe dotar de coherencia completa al juego de hechos y culpabilidades si echamos mano de la epistemología expuesta supra, de modo que el hecho sea, en todas sus dimensiones, hecho de la empresa ${ }^{37}$.

La pregunta, entonces, que podríamos hacernos es la siguiente: ¿por qué podemos considerar hecho propio de la empresa el de confeccionar (o no, omisivamente) un sistema de cumplimiento y, por el contrario, no podemos considerar hecho propio el surgido de la acción típica de uno de sus responsables

ponsabilidad penal y procesal de las personas jurídicas, Memento experto, Madrid, 2015, pp. 44-45.

35 DE LA MATA BARRANCO, N.J.: "Los protocolos...", cit., p. 291. Esta afirmación engrana con la ya clásica propuesta de TIEDEMANN ("Responsabilidad penal de las personas jurídicas", en Hurtado Pozo, J. (coord.), Responsabilidad penal de las personas jurídicas, Lima, 1997, p. 116) sobre culpabilidad por defecto en la organización. Véanse sobre esto las teorías acerca del injusto propio de la persona jurídica expuestas por GÓMEZJARA DÍEZ (“La culpabilidad...”, cit., pp. 123 y ss.).

36 DE LA MATA BARRANCO, N.J.: "La exclusión...", cit., p. 90.

37 Esta presunción abriría, como es evidente, el debate sobre el ne bis in idem. Véase, por ejemplo, SILVA SÁNCHEZ, J.M.: "La evolución ideológica...", cit., pp. 137-138. 
o trabajadores? En ambos casos cabría una interpretación figurativa de individuos concretos que hacen o dejan de hacer (un directivo que decide, o no, implementar un sistema de cumplimiento). Pero, inversamente, en ambos casos cabe una interpretación estructuralista del sujeto empresa como sujeto complejo que hace o deja de hacer ${ }^{38}$.

Por lo tanto, no solo no habría lógica vicarial, sino que ni siquiera el hecho propio debería ser un hecho omisivo de ausencia de vigilancia, ya que el hecho típico cometido por una persona física podría ser también el hecho típico cometido por la empresa misma (sería un hecho propio de la empresa, como es hecho de la persona física el cometido por alguna parte de su cuerpo).

Pero la flexibilización de la dogmática que pretendemos, como exponíamos, está determinada por el objetivo anunciado, que pretende evitar la parálisis del sistema penal en el caso de que las empresas implementen sistemas de cumplimiento eficaces solo a priori. Por ello, nuestro empeño pasa por desanclar la función de los sistemas de cumplimiento de la antijuridicidad para amarrarla a la culpabilidad. Siguiendo este interés, sería muy útil la interpretación que propone FERNÁNDEZ TERUELO: deberían disociarse dos momentos en lo exigido por la ley para verificar la responsabilidad penal de las personas jurídicas. $\mathrm{Y}$ es que lo exigido en el artículo 31bis.1 CP para que la responsabilidad recaiga en la persona jurídica (incumplir los "deberes de supervisión, vigilancia y control”) no necesariamente tiene que ser lo desarrollado -en una suerte de interpretación auténtica- en el 31 bis. 2 CP y, por tanto, no necesariamente debe

38 Esta cuestión debe relacionarse con el perfilamiento del sujeto-empresa que proponíamos antes, y que nos hace deambular entre concepciones funcionalistas. Pero es que, para el caso de las empresas, tal concepción funcionalista no arrastra los riesgos que implica para las personas físicas, ya que, como exponíamos, las personas jurídicas son producto del derecho. No hay sustrato biológico que obligue a contener la mirada funcionalista hacia la empresa, ya que esta es esencialmente explicable en términos de funcionalidad jurídica. 
sustanciarse en un sistema de cumplimiento. El autor considera que se trata de dos momentos distintos, de tal modo que, no habiéndose cumplido tal deber de supervisión, vigilancia y control en las personas físicas, puede haberse cumplido el requisito del modelo de gestión en la empresa. O al revés: no existiendo un compliance, puede haberse actuado conforme a los deberes de supervisión, vigilancia y control, de modo que no habría responsabilidad de la empresa ${ }^{39}$.

Si hacemos nuestra esta especulación, aunque dándole un valor dogmático distinto, podemos considerar, por un lado, el deber de supervisión y, por otro, la implantación de un compliance. Aprovechamos, así, la disección que hace FERNÁNDEZ TERUELO para proyectarlo dogmáticamente en un sentido distinto, que aproveche a nuestros objetivos. De este modo, el deber de vigilancia podría formar parte de la tipicidad, pero la implantación de un compliance no, ya que tiene implicaciones de más calado, más estructurales, más permanentes que, a nuestro juicio, deberían integrarse en el nivel dogmático de la culpabilidad.

En definitiva, no creemos que la implementación del compliance determine la ausencia de tipicidad o antijuridicidad, ya que la actuación que, desde cierta perspectiva, podemos describir como de la persona física, en realidad lo es de una persona física investida con las motivaciones relacionales de la empresa. Por ello, no creemos que la responsabilidad sea vicarial, esto es, no se contagia, sino que es un hecho propio de la empresa. Pero tampoco creemos que el hecho propio (omisivo) que genera la imputabilidad sea el compliance, sino que, como señalábamos, el hecho propio de la empresa es el que, desde otras epistemologías, podríamos decir que desarrolla físicamente un individuo que actúa, además, en su beneficio.

39 FERNÁNDEZ TERUELO, J.: "Responsabilidad penal de las personas jurídicas: el contenido de las obligaciones de supervisión, organización, vigilancia y control referidas en el art. 31 bis 1. b) del Código Penal español", en Revista electrónica de ciencia penal y criminología, $\mathrm{n}^{\mathrm{o}}$ 21, 2019, p. 16. 
Y, así, el hecho propio de la empresa no se extingue por la existencia de un compliance con todas las garantías. El hecho subsiste y señala la antijuridicidad, mientras que el compliance marca la sensibilidad de la empresa a la motivación de la norma penal (en concreto, como veremos, a la norma penal incumplida), que no es lo mismo que formar parte de la tipicidad específica que protege un determinado bien jurídico.

De este modo, no consideramos los arts. 31 bis 2 y 4 como causas de atipicidad que, en sentido positivo, estarían desarrollándose, tácitos, transversales a todos los preceptos imputables a las personas jurídicas, ya que el compliance no debe comprenderse, a nuestro juicio, como una barrera añadida para la defensa del bien jurídico concreto que el precepto pretende proteger. Por el contrario, los arts. 31 bis 2 y 4 pueden considerarse como causas genéricas de exención de la pena que, referidas al perfil del sujeto activo, señalan el límite de la motivación de la persona colectiva.

\subsection{Sistema de cumplimiento y culpabilidad}

Las elevaciones a categorías dogmáticas de los sistemas de cumplimiento han seguido senderos diversos entre la doctrina. Teleológicamente, podemos comprender que, efectivamente, "los 'Corporate Compliance Programs' (medidas eficaces, modelos de organización y gestión, modelos de organización y prevención, manuales de cumplimiento normativo; mejor, protocolos de prevención de delitos) sirven en Derecho penal para esto: para demostrar un hacer diligente en todos los procedimientos empresariales con el objetivo prioritario (...) de evitar que la persona jurídica pueda cometer, o ser utilizada para cometer, un delito" $"$.

Desde esa caracterización del sistema de cumplimiento, sin embargo, el encaje dogmático puede variar y, en ello, los efectos ulteriores también. La verificación de un programa de cumplimiento eficaz a priori podría implicar la ausencia de ti-

40 DE LA MATA BARRANCO, N.J.: "La exclusión...”, cit., p. 100. 
picidad o de título de imputación por no concurrir dolo o aun imprudencia ${ }^{41}$. Sin embargo, en atención a los fines expuestos desde el inicio de este trabajo, así como a la caracterización elemental de la empresa que hemos propuesto, la contorsión de la dogmática que más funcional nos parece es la que apunta a la relación entre los programas de cumplimiento y la ausencia de culpabilidad $^{42}$.

$\mathrm{Al}$ margen de los intereses funcionales que vienen veteando este trabajo, concurren también una serie de lógicas formales que abonan nuestras intenciones. En este sentido, DE LA CUESTA ARZAMENDI indica que "en un Derecho penal respetuoso de los principios limitadores de la potestad punitiva del Estado, la imputación típica (objetiva y subjetiva) no basta para la proclamación de la responsabilidad penal", aunque es cierto que "la imputabilidad de las personas jurídicas no deja de ser problemática; y lo mismo cabe decir de las propuestas de dotar de contenido específico a su culpabilidad" ${ }^{3}$. Por tanto, se trata

41 DE LA MATA BARRANCO ("La exclusión...", cit., p. 91), partiendo de la inspiración italiana de la norma española y, por tanto, con arreglo a una interpretación acorde con tal precedente, considera que "esta exención (...) no debe interpretarse al modo de las habituales causas de exclusión de responsabilidad del artículo 20 del Código por ausencia de ilicitud o culpabilidad, sino como ausencia de hecho injusto por faltar título de imputación, doloso o imprudente, que pueda generar responsabilidad". Asimismo: "la exclusión de dicha responsabilidad; simplemente por ausencia de injusto típico" (DE LA MATA BARRANCO, N.J.: "Los protocolos...”, cit., p. 290). Y también: "cuando una persona jurídica tiene establecidos controles respecto de un riesgo penal específico que resultan idóneos para conjurar el mismo (...) existirá una atipicidad de la conducta de la persona jurídica" (GÓMEZJARA DÍEZ, C.: "La culpabilidad...", cit., p. 113).

42 Sobre los modelos teóricos más notorios acerca de la culpabilidad de las personas jurídicas, véase BAJO FERNÁNDEZ, M.: "Vigencia de la RPPJ en el derecho sancionador español", en BAJO FERNÁNDEZ, M., FEIJOO SÁNCHEZ, B. J. Y GÓMEZ-JARA DÍEZ, C.: Tratado de responsabilidad penal de las personas jurídicas: adaptado a la Ley 1/2015, de 30 de marzo, por la que se modifica el Código Penal, Cizur Menor, 2016, pp. 44-45.

43 DE LA CUESTA ARZAMENDI, J.L: "Responsabilidad penal de las personas jurídicas en el Derecho español”, en DE LA CUESTA ARZAMENDI, J.L. (dir.) y DE LA MATA BARRANCO, N.J. (coord.), Responsabilidad Penal de las Personas Jurídicas, Cizur Menor, 2013, pp. 60-61. 
de indagar en aquellos elementos que permitan erigir la responsabilidad penal sobre su propia culpabilidad ${ }^{44}$.

En tal sentido, el Tribunal Constitucional ha señalado que el principio de culpabilidad es esencial en un Estado de Derecho a efectos del funcionamiento del ius puniendi (STC 59/2008). Asimismo, en la STC 129/2003 (FD 8), el Tribunal Constitucional deja claro que las personas jurídicas tienen capacidad de culpabilidad, por lo que parece evidente que se hace necesario un modelo de fijación de la culpabilidad de las personas jurídicas para que sea legítima la imposición de una pena, o aun de una sanción administrativa ${ }^{45}$. Y, sin salir de esta lógica, cabría argumentar, en sentido contrario, que las empresas pueden no ser culpables. Por tanto, sería conveniente que existiera una previsión legal que atienda a esta posibilidad dogmática ${ }^{46}$. En este

44 Dice la STS 154/2016 que "sólo a partir de una indagación por el Juez instructor de la efectiva operatividad de los elementos estructurales y organizativos asociados a los modelos de prevención, podrá construirse un sistema respetuoso con el principio de culpabilidad". Sobre este sentido en la interpretación del Tribunal Supremo, véase GÓMEZ-JARA DÍEZ, C.: "La culpabilidad...", cit., pp. 180 y ss.

45 "La perspectiva dogmática para resolver esta cuestión debe asentarse en los principios básicos que permiten imputar penalmente un hecho" (DE LA MATA BARRANCO, N.J.: "La exclusión...", cit. p. 89). Se trata de condicionantes con los que no juega el modelo anglosajón, que "nunca se ha planteado especiales problemas de tipo dogmático para admitir la responsabilidad penal de la empresa" (FERNÁNDEZ TERUELO, J.: "Regulación vigente...", cit., p. 64). Sin embargo, la dogmática, como venimos argumentando, no debe ser obstáculo para la operatividad, sino una guía para hacerla más sostenible.

46 Aunque en nuestro sistema penal debe deducirse la definición de imputabilidad a sensu contrario (CASANUEVA SANZ, I.: La imputabilidad, el consumo de drogas y su regulación jurídico-penal. una revisión desde las ciencias de la salud (Tesis doctoral), Bilbao, 2013, p. 212), la construcción doctrinal derivada del art. $20 \mathrm{CP}$ apunta a una doble necesidad. De un lado, debe darse la capacidad cognitiva y, por otro, la función volitiva (HIGUERA GUIMERÁ, J.F.: "La prueba pericial psiquiátrica en los procedimientos judiciales penales y la medicina forense en España. Una respetuosa llamada 'urgente' de atención", en La ley penal: revista de derecho penal, procesal y penitenciario, $\mathrm{N}^{\mathrm{o}} 24,2006$ ). 
trabajo pretendemos sustanciar tal previsión legal en los programas de cumplimiento ${ }^{47}$.

Para abordar la dimensión de la culpabilidad empresarial asociada, en su caso, a los programas de cumplimiento, es necesario fijar esquemáticamente el horizonte conceptual en el que pretendemos argumentar. Con MIR PUIG, convenimos que, desde VON LITSZ, el concepto de culpabilidad fue evolucionando hasta asentarse sobre los postulados finalistas que, definitivamente, normativizaron la culpabilidad ${ }^{48}$. Nuestro Código penal asumiría entonces, por razón de las inimputabilidades legales previstas, un sistema de culpabilidad normativo que integra en lo penal determinadas alertas científicas. En este sentido, las exigencias para la culpabilidad (concepto que el propio MIR PUIG pone en cuarentena y considera sustituible por el de "imputación personal") pasan por señalar la imputabilidad, esto es, "poder actuar de otro modo", "la posibilidad de conocimiento de la antijuridicidad del hecho" y, por último, "la ausencia de causas de exculpación" $"$. En estas coordenadas, lo problemático es dar contenido material a la carga normativa que integra tal

47 Recordamos nuestra inspiración hacia la dogmática: pretendemos funcionalizar la dogmática en atención a la preocupación criminológica anunciada. Descartamos, por ello, las tesis de la responsabilidad por el hecho ajeno, las tesis de la ausencia de tipicidad por verificarse, a su vez, la ausencia de un protocolo de prevención de riesgos delictivos eficaz, así como descartamos las tesis de la comisión por una suerte de imprudencia sui generis (el compliance como norma de deber de cuidado de la empresa). La razón, insistimos, no surge de un idealismo principialista, sino de una adecuación de la dogmática a la necesidad social de evitar que las empresas, aun con compliance, puedan subsistir como focos de peligro criminal.

48 MIR PUIG, S., Derecho penal. Parte general, Barcelona, 2007, pp.522 y ss. También, desde una perspectiva genealógica, puede verse BACIGALUPO SAGESE, S.: "Culpabilidad y prevención en la fundamentación del derecho penal español y latinoamericano", Historia. Instituciones. Documentos, n. 6, 1979, pp. 11-32.

49 MIR PUIG, S., Derecho penal..., cit., p. 527. Véase también, por todos, MUÑOZ CONDE, F. y GARCÍA ARÁN, M., Derecho penal. Parte General, Valencia, 2015, p. 376; y QUINTERO OLIVARES, G., Parte General del Derecho Penal, Cizur Menor, 2010, p. 558. 
culpabilidad ${ }^{50} \mathrm{y}$, en concreto, a la que toca a las personas jurídicas. Sobre eso -y con las pretensiones pragmáticas que anunciábamos desde el inicio- ensayaremos en lo siguiente.

De este modo, debemos tomar "la concepción de la culpabilidad como disposición interna del sujeto hacia la norma (esto es, como el reproche ético-social a un sujeto libre o con motivabilidad normal)" "51. Además, como indica BACIGALUPO, "es evidente que la culpabilidad, se la defina como se la defina, es estrictamente individual y de carácter personal, por lo que no puede afectar más que al sujeto en quien concurren". Sin embargo, "el legislador no ha elaborado un modelo de imputación en sentido estricto" ${ }^{52}$, por lo que las hipótesis doctrinales resultan relativamente desancladas de una referencia literal segura.

Así, sintéticamente, GÓMEZ-JARA propone una panorámica -incluso con trazas genealógicas- de las concepciones de la culpabilidad de las personas jurídicas ${ }^{53}$. Aún más esquemáticamente, pueden distinguirse dos modelos de culpabilidad de las personas jurídicas: por un lado, la del defecto de organización; por otro lado, la culpabilidad por cultura empresarial del incumplimiento ${ }^{54}$. Aupado a la teoría del defecto de la organización $^{55}$ de TIEDEMANN, ZUGALDÍA ESPINAR señala dos

50 Señalan MUÑOZ CONDE y GARCÍA ARÁN (Derecho penal... p. 379) que el salto cualitativo que da nuestro concepto de culpabilidad es que ya no surge desde el individuo, sino que debe integrar la dimensión social.

51 PÉREZ MACHÍO, A.I., Responsabilidad penal ..., cit., p. 69.

52 BACIGALUPO SAGESSE, S.: "Los criterios de imputación..." cit., p. 5.

53 Especialmente relacionada con los argumentos esgrimidos en este trabajo, debe atenderse a la teoría de la voluntad especial de HAFTER, a la culpabilidad aditiva según BUSCH o a la culpabilidad desde la estructura en relación con la evitabilidad de los fallos organizativos en FRISCH (cfr. GÓMEZ-JARA DÍEZ, C.: "La culpabilidad...", cit., pp. 153 y ss.).

54 Véase también PÉREZ MACHÍO, A.I.: La responsabilidad penal..., cit., pp. 75 y ss.

55 "Respecto de la culpabilidad se requiere -según la doctrina dominante-que todo ello ocurra como consecuencia de haber omitido la persona jurídica - de forma contraria al deber- la adopción de alguna de las medidas de precaución y de control (defecto de organización)" (ZUGALDÍA ESPINAR, J.M. "Societas delinquere potest...", cit., p. 5). 
tipologías de culpabilidad: por la estructura empresarial misma (culpa in constituiendo) o por la de la selección y formación de los directivos o empleados (culpa in eligendo vel in instruien$d o)^{56}$. En cualquier caso, nada hay en nuestro Código penal que invite a las personas jurídicas a circunvalar las previsiones del artículo 20, por lo que sería necesario adaptar la actual construcción doctrinal de la culpabilidad para trasladarla a los entes colectivos $^{57}$.

Para PÉREZ MACHÍO, el "defecto de organización" formaría parte de la tipicidad, mientras que "la culpabilidad de la persona jurídica consiste en un reproche similar (a la persona física), como consecuencia de la infracción del derecho o, dicho en otras palabras, como consecuencia de la permanencia de una determinada cultura empresarial de incumplimiento de la legalidad". De esta manera, "la culpabilidad de las personas jurídicas consistirá, así, en el hecho de no haber organizado su actividad conforme a las exigencias del ordenamiento, siendo tal falta de organización la causa posterior de la comisión del delito"58. Dando por buena esta definición de la culpabilidad empresarial, parece oportuno modular en parte su encaje dogmático conforme a los presupuestos conceptuales que hemos expuesto supra (1.2): el hecho propio delictivo podría ser el hecho propio de la persona física mismo. El defecto de organización -al menos el previsto en los puntos 2 y 4 del art. 31 bis $\mathrm{CP}$ - no formaría parte de la tipicidad, sino que sería el marcador de la cultura de incumplimiento en unos parámetros de vigencia normativa, en concreto los de una ética social, material y heteronormativa ${ }^{59}$.

56 ZUGALDÍA ESPINAR, J.M.: “Teorías jurídicas del delito...”, cit., p. 28.

57 "La culpabilidad de las personas jurídicas así entendida obliga a adaptar la dogmática naturalista a los nuevos desafíos, llenando las lagunas como consecuencia de estar hechas a la medida de las personas físicas" (JUANES PECES, A.: "Introducción...", cit., p. 14).

58 PÉREZ MACHÍO, A.I.: La responsabilidad penal..., cit., pp. 76-77.

59 La empresa es, entonces, un actor autónomo inserto en una cultura de comportamiento, esto es, en una ética (véase, en este sentido, ZUGALDÍA ESPINAR, J.M., La responsabilidad criminal de las personas jurídicas..., cit., p. 25). Frente a la idea de la "ciudadanía corporativa" de la empresa 
Si tomamos como la principal causa de culpabilidad la posibilidad de comportarse de otro modo ${ }^{60}$, podemos colegir con cierta solvencia que, efectivamente, la empresa como complejo estructural puede ser valorada conforme a cómo su estructura condiciona sus márgenes de actuación ${ }^{61}$. En esta disyuntiva, caben las dos posibilidades sobre el hecho propio expuestas. O bien se considera que el hecho propio de la empresa es el mismo que el de la persona física. O bien, siguiendo la apreciación disociativa de momentos que tomábamos de FERNÁNDEZ TERUELO, la empresa actúa omitiendo su deber de supervi-

(GÓMEZ-JARA DÍEZ, C.: "La culpabilidad...”, cit., p. 97), proponemos la idea de la empresa que puede afectar bienes jurídicos en su sentido ético material. Lo cierto es que, en el caso de las empresas, el sentido ético material está señalado, a diferencia de lo que sucede en las personas físicas, por su programación jurídica, esto es, por el compliance.

60 Es necesario notar en este punto que consideramos la inimputabilidad como parte de la culpabilidad, y no como un presupuesto de esta. Esto es, la inimputabilidad no es independiente de la culpabilidad según un perfil permanente y previo, sino que se valora en sí misma en relación con el hecho. Véase, sobre esto, MARTÍNEZ GARAY, L.: La imputabilidad penal. Concepto, fundamento, naturaleza jurídica y elementos, Valencia, 2005, pp. 78 y ss.

61 "Entendida la culpabilidad de las personas físicas como el juicio de reproche que se le hace al autor del delito por su capacidad de ser motivado por la norma jurídico-penal y de orientar sus comportamientos conforme a derecho, en cuanto concurran en él condiciones normales que le permitan comprender la ilicitud del hecho y comportarse conforme a dicha comprensión, idéntico presupuesto debe predicarse de la culpabilidad de las personas jurídicas, adaptada, eso sí, a las peculiaridades y naturaleza de las mismas" (PÉREZ MACHÍO, A.I., La responsabilidad penal ..., cit., p. 190). Nos desmarcamos, por las razones funcionales que condicionan este trabajo, de las posiciones que desestiman que "los programas de autorregulación corporativa" sirvan de "fundamento de la imputación de la persona jurídica (ni como) sustrato de una pretendida culpabilidad de empresa" (FERNÁNDEZ TERUELO, J.: "Regulación vigente...", cit., p. 69). Tampoco consideramos para las argumentaciones que desarrollaremos en lo siguiente aquellas posiciones que hacen del compliance un medidor del juicio de imputación objetiva, en tanto que "el modo de estar (des)organizada la persona jurídica ha generado un riesgo jurídicamente desaprobado, que se ha realizado en un resultado consistente en el favorecimiento de la actuación de la persona física y finalmente, en el resultado delictivo producido por ella" (FERNÁNDEZ TERUELO, J.: "Regulación vigente...", cit., p. 69). 
sión, vigilancia y control de modo suficiente como para considerar que aquella omisión es el hecho típico propio. En cualquiera de los dos casos, y en un segundo momento, podemos considerar que la empresa que implementa un programa de cumplimiento no pudo comportarse de otro modo, esquivando su culpabilidad. Lo relevante, entonces, es esto: el compliance marca un estado relativamente permanente de imputabilidad, no un hecho o una acción aislada.

Esta evitabilidad de la culpabilidad se debe relacionar, en todo caso, con la eficacia concreta del compliance respecto del hecho delictivo cometido, y no ya con el compliance como una estructura abstracta que sea eficaz, o no, en bloque ${ }^{62}$. Esto es, el compliance señala los límites de programación en las rutinas empresariales, de modo que las acciones excesivas respecto de aquel deben interpretarse como fenómenos incomprensibles para la empresa. La persona jurídica, entonces, no otorgaría sentido, en sus rutinas internas, a un actuar que resultase contrario a sus protocolos ético-sociales; si la empresa no es capaz de entender tal acción, podríamos concluir que ha realizado una acción típica de la que no puede responder por ausencia de culpabilidad, ya que no podría controlar su comportamiento fuera de esos esquemas de acción, que conforman su "naturaleza". Sería inimputable en relación con ese hecho propio. Dicho de otro modo, el compliance marcaría un campo de acción de libertad que haría ininteligible para la empresa la ruptura del mandato

62 Esto entronca con la exigencia de contenidos concretos del sistema de cumplimiento a los que ya aludía la fiscalía (Circular 1/2016 FGE). Una orientación detallada de contenidos puede verse en DE LA MATA BARRANCO, N.J.: "Los protocolos de prevención...", cit. y "La actuación conforme a protocolos de prevención de delitos como causa de exención de responsabilidad penal", en DE LA CUESTA ARZAMENDI, J.L. (dir.) y DE LA MATA BARRANCO, N.J. (coord.), Responsabilidad Penal de las Personas Jurídicas, Cizur Menor, 2013, pp. 249-266. Véase también ZUGALDÍA ESPINAR, J.M.: "Teorías jurídicas del delito...”, cit., pp. 29 y ss. y ABIA GONZÁLEZ, R. y DORADO HERRANZ, G.: Implantación práctica de un sistema de gestión de cumplimiento - compliance management system, Cizur Menor, 2017. 
penal; marcaría una suerte de limitación de las capacidades volitivas y comprensivas de la estructura empresarial ${ }^{63}$.

Inversamente, si una empresa no tiene implementado un sistema de cumplimiento, podemos considerar que es capaz de comprender y generar una expectativa razonable en relación con hechos típicos producidos en su interior, ya que su programación no incorpora una ética -un ethos, unas rutinas- que eviten comprender aquellos hechos. Su programación estructural alcanza esa libertad. Esto es, sus rutinas de comportamiento contemplan esas posibilidades y, por tanto, la empresa decide quebrantar (o no) la norma penal, por lo que tales delitos serían perfectamente imputables a tal empresa a través del art.31bis.1 CP.

La modulación en relación con la culpabilidad de las personas físicas es necesaria para funcionalizar la culpabilidad empresarial: tomamos por defecto la normalidad cognitiva y volitiva en las personas físicas, salvo prueba en contrario; pero lo importante es considerar esta capacidad cognitiva y volitiva respecto de hechos concretos. Un individuo, por tanto, no es inimputable en bloque, sino que lo es según su capacidad cognitiva y volitiva respecto de un hecho. Con las empresas sucedería lo mismo, pero la capacidad cognitiva o volitiva, sus parámetros de normalidad/excepcionalidad, digamos, lo marca el sistema de cumplimiento (a efectos de culpabilidad, sin perjuicio de que la normativa de sociedades las considere como sociedades regulares): una empresa con compliance no puede conocer ni querer la realización de hechos delictivos previstos y conjurados por su programa interno, "al no poder serle exigida a la persona jurídica una organización diferente para la prevención y control de ilícitos penales" ${ }^{64}$. Su programación de actuación, su circuito neuronal, no procesaría tales hechos $\mathrm{y}$, por tanto, si se produjesen, sería sin que la empresa hubiera podido comportarse de otro modo (por un cortocircuito interno, digamos).

63 En el caso de las personas jurídicas, no habría entonces una presunción de normal capacidad para dirigir libremente su comportamiento, sino que sería la normativa la que señalaría, construiría, la normal capacidad.

64 PÉREZ MACHÍO, A.I., La responsabilidad penal..., cit., p. 191. 
Por tanto, bajo la dogmática de nuestro sistema penal, debemos descifrar la culpabilidad de la empresa por un hecho propio, ya que ha quedado evidenciado que así lo exige la posibilidad de su reprobación penal. Y, en esa fase, la valoración de su culpabilidad depende de la reducción conceptual de acciones que la empresa sistematice -programe como posibles-. La implementación de un modelo de prevención de delitos es la sustanciación normativa que señala una pauta de rutinas empresariales concreta, y que deja fuera de la comprensión de la persona jurídica las afectaciones a bienes jurídicos (todas ellas, si el sistema es enteramente eficaz a priori).

Sucede, con esta interpretación de la culpabilidad empresarial, que abandonamos las lógicas de disociación subjetiva (persona jurídica versus personas físicas en su interior). La alternativa interpretativa pasa por concebir en su entereza y complejidad a la empresa, que actúa inserta en una programación que, a su vez, marca sus capacidades cognitivas y volitivas, independientemente del tamaño ${ }^{65}$. Y de esto se deriva que, bajo ciertos presupuestos, cabe un juicio de reproche ético sobre la empresa misma que es la razón última de su culpabilidad ${ }^{66}$.

65 No nos parece oportuno -y también seguimos aquí a PÉREZ MACHÍO ( $L a$ responsabilidad penal..., cit., pp. 194-195)-adelantar el momento de la imputabilidad penal a la capacidad (o no) de implementar programas de cumplimiento, de tal modo que las empresas de pequeñas dimensiones no tendrían posibilidad de implementar un sistema de cumplimiento y resultarían, por ello, inimputables. Nos parece incompatible con la literalidad del art. 31 bis.3 CP, que prevé expresamente las funciones de supervisión en las empresas de pequeñas dimensiones. Pero, más allá, nos parece que, independientemente del tamaño de la empresa, lo cierto es que la estructura misma determina el actuar de las personas físicas en su interior, ya que operan en un tejido jurídico dispositivo de diferente envergadura, pero con las mismas funciones. Esto es lo que realmente señala sus parámetros de acción efectiva.

66 Puede consultarse, con unas bases compartidas, aunque con un desarrollo distinto, la razón de "culpabilidad por reprochabilidad ético-social empresarial” en DANNECKER (cfr. GÓMEZ-JARA DÍEZ, C.: "La culpabilidad...”, cit., pp. 158 y ss.). 
SILVA SÁNCHEZ se muestra refractario a validar los presupuestos de estas elucubraciones e indica que la doctrina se ha afanado por construir un "concepto funcional de culpabilidad (...) por defecto de organización"; pero estos intentos "se distancian radicalmente de cualquier concepto de culpabilidad como juicio de reproche que presuponga autoconciencia y libertad". Sería muy complicado, en definitiva, localizar en la "culpabilidad por defecto de la organización (...) una culpabilidad en sentido estricto de la persona jurídica". Se trataría, de una "transferencia de responsabilidad a la persona jurídica por el hecho culpable de las personas físicas" ${ }^{\circ 7}$.

Sin embargo, al dotarnos de un criterio ético distinto al que presupone SILVA SÁNCHEZ o, en general, al criterio ético formalista kantiano, cabría un juicio de reproche ético totalmente operativo entre las personas jurídicas y entes colectivos. Para ello, sería necesario apelar a una ética heteronormativa que se formule como un sistema de respeto a través de lo social ${ }^{68}$, en contextos materiales determinados, y que sería antagónica a la ética formalista de corte humanista. La fórmula "posibilidad de comportarse de otro modo", de hecho, recoge bien esta evocación de la libertad en su sentido negativo, esto es, deducida de las determinaciones de la persona en un entorno complejo, y no como atributo positivo, como don.

Así, la empresa puede someterse a estos parámetros éticos, que obvian esa incierta naturaleza insondable de lo humano como fundamento ${ }^{69}$. Se trataría de una ética inducida desde el

67 SILVA SÁNCHEZ, J.M.: "La evolución ideológica...”, cit., pp. 139-140.

68 Más extensamente, sobre la tradición ética que ampara esta posición, véase PÉREZ GONZÁLEZ, S.: "El bien jurídico penal...", cit. En esta concepción del delito, la antijuridicidad referiría una ética material que se desvela según la afectación efectiva a individuos concretos.

69 Se trata, en definitiva, de mantener el equilibrio entre conceptos que surgen de la tradición humanista para volcarlos a una realidad funcional. Así, sobre la insuficiencia del concepto bio-psicológico de culpabilidad, puede verse ZUGALDÍA ESPINAR, J.M.: "La reforma del sistema de responsabilidad criminal de las personas jurídicas. Consideraciones críticas", Revista de la 
entorno, desde las condiciones de existencia, desde las determinaciones materiales. En contextos concretos, por tanto, se activa un proceso decisional que puede evaluarse según las inercias del todo en el que emerge la decisión. La decisión no es, entonces, el resultado de un estado normal de libertad, sino que, inversamente, la libertad, como volición, es un momento aislable en un devenir de condicionantes que, mediante la ética, sometemos a cierta valoración social ${ }^{70}$. $\mathrm{Si}$, en el ámbito empresarial, puede determinarse el entorno de rutinas respetuosas (los protocolos de cumplimiento pueden comprenderse como codificación formal de esas rutinas a efectos de la programación empresarial), entonces cabe un reproche ético porque puede valorarse la relación irrespetuosa de tal sujeto jurídico con su entorno.

Si nos despegamos, entonces, de la introspección humana como fuente originaria de la ética entre las personas físicas (y que KANT derivaba al juego de moral y libertad), podemos reevaluar el reproche de eticidad según una ética material, social, que formule deberes prácticos. Y, en esas coordenadas, tan evaluable es un individuo como un ente colectivo ${ }^{71}$.

La motivación de las personas físicas resulta relativamente inescrutable desde una criminología normativamente más abierta y discutida. Pero la motivación de las personas jurídicas -su horizonte ético en el sentido que aquí le damos a la

Facultad de Derecho de la Universidad de Granada, n. 16-18, 2013-2015, p. 1509, aunque sin que esta insuficiencia le lleve a una consideración autopoiética de la culpabilidad: "«cargar con el elemento humano» es ontológicamente inevitable para cualquier teoría de la imputación de las personas jurídicas, dado que éstas solo pueden actuar a través de personas físicas" (ZUGALDÍA ESPINAR, J.M.: "Modelos dogmáticos...", cit., p. 3).

70 En PÉREZ GONZÁLEZ, S.: "El bien jurídico penal...”, cit., pp. 18 y ss., se sostiene que esta es una ética construida desde el sujeto corpóreo, pero precisamente por su estar en el mundo, no por su ser trascendente. Por ello es posible una extrapolación operativa hacia las personas colectivas.

71 Esta ética material, contextualizada, no persigue los fines universalistas de la ética kantiana. Por ello, el código ético de una empresa puede no parecerse al de otra, ya que las rutinas debidas para evitar el daño en el entorno surgen de prácticas concretas diferenciadas, no de morales cerradas. 
ética- puede quedar codificada en clave de programas de cumplimiento. La capacidad de reproche ético depende de cómo su estructura interna (sustrato permanente) atiende, o no, al entorno normativo. Y, en concreto, la imputabilidad en relación con un hecho depende directamente de una codificación restrictiva de acciones posibles en el interior de la empresa. Por ello, si no hay sistema de cumplimiento, la imputabilidad sería total.

Dice PÉREZ MACHÍO, en este sentido, que no puede obviarse la clave de acción propia de las personas jurídicas por razones político-criminales referidas a "la inconmensurable relevancia de su actividad"72. Y esta relevancia inconmensurable es lo que conecta al derecho penal con la necesidad de fiscalizar las acciones empresariales y que, de este modo, pueda calibrarse tal relevancia ${ }^{73}$ (no en vano apuntábamos que la forma jurídica empresa reconstruye el sistema económico y social a partir del siglo XVIII).

De este reproche ético-social se derivan, a su vez, consecuencias prácticas. En ello radica la culpabilidad por estructura organizada deficitaria, pero esta sería un indicio de aquella. Esto es, el Código penal exige, para eximir de responsabilidad, "modelos de organización idóneos para prevenir delitos", pero el cumplimiento normativo sería, por esa vía literal, el cumplimiento de la norma ético-social; el compliance-alojado en este punto dogmático- no debe proponer, necesariamente, un adelantamiento técnico de la barrera punitiva, sino unos protocolos de evitación de daños que, técnicamente, exigen una disciplina interna para evitar la afectación material a bienes jurídicos.

De este modo, la cultura de cumplimiento señala la inimputabilidad, pero evaluable en relación con cada hecho concre-

72 PÉREZ MACHÍO, A.I.: La responsabilidad penal ..., cit., p. 65.

73 Como decía DURKHEIM, en un decimonónico exceso sociologicista, "una crisis económica, un golpe bursátil, incluso una quiebra, pueden desorganizar mucho más gravemente el cuerpo social que un homicidio aislado" (DURKHEIM, E.: De la división del trabajo social, trad. David Maldavsky, Buenos Aires, (1893) 1967, p. 69) 
to. $\mathrm{Y}$ el cumplimiento, por tanto, debe verificarse por criterios de asunción de la norma ético-social en un sentido material; la manera, entonces, de verificar formalmente esto pasa por implementar un protocolo de prevención del delito en sentido antijurídico material, y no como simple evitación de la forma típica ${ }^{74}$.

El modelo de prevención debe atender, por ello, no a la vigencia de la norma jurídica, no al deber del ciudadano corporativo, sino a la vigencia de la norma ética, que debe quedar mapeada en términos de antijuridicidad material. Si ese mapa de acciones posibles, de límites de conocimiento y voluntad de la estructura, descarta caminos concretos de antijuridicidades materiales concretas, no hay culpabilidad. Sin compliance, sin embargo, no hay límites de acción y, por tanto, hay culpabilidad $\mathrm{y}$, con ella, pena.

\section{Vaivén dogmático del artículo 129 del Código penal}

El Código penal de 1995 estableció como consecuencias jurídicas aplicables a las personas jurídicas las consecuencias accesorias, reguladas en su art. 129. Antes de esto, el Código penal anterior ya preveía de modo disperso medidas sobre entes colectivos, como el cierre de locales, la disolución de organizaciones o la suspensión de actividades ${ }^{75}$. La diferencia cualitativa de la irrupción del art.129 CP en 1995 fue, por tanto, esencialmente de sistematización: señalar en un artículo concreto -al

74 Por resultar ilustrativos: un compliance, a nuestro juicio, no debe trasladar las prohibiciones de la norma penal, sino que debe confeccionar, además del resto de requisitos legalmente exigidos, un código disciplinario que conjure caminos hacia la antijuridicidad material. No debe, por ejemplo, prohibirse la "revelación de secretos de empresa", sino las situaciones que, en modos diversos, pueden llegar a afectar negativamente a otros individuos a través del mercado, como, por ejemplo, no usar un sistema de cifrado compartido para almacenar datos relevantes.

75 DE LA CUESTA ARZAMENDI, J.L.: "Personas jurídicas, consecuencias accesorias y responsabilidad penal", en ARROYO ZAPATERO, L. y BERDUGO GÓMEZ DE LA TORRE, I. (coords.), Homenaje al Dr. Marino Barbero Santos: “in memorian”, Vol. 1, 2001, pp. 968-969. 
margen de otras disposiciones de naturaleza similar en la parte especial ${ }^{76}$ - la conceptualización como "consecuencias accesorias" de una serie de consecuencias jurídicas aplicables a empresas, sociedades, asociaciones y fundaciones.

Sin embargo, la misma exposición de motivos del Proyecto de 1992 ya anunciaba que las consecuencias accesorias "no tendrán fácil acomodo ni entre las penas ni entre las medidas de seguridad", y la doctrina las consideró de modo desigual, aunque señalando en todo caso desajustes importantes ${ }^{77}$. Estos desajustes condujeron a una sistemática inaplicación del art. 129 $\mathrm{CP}^{78}$.

Entre la vacilante aplicabilidad del art. $129.1 \mathrm{CP}$, emergía, sin embargo, el extinto art. $129.3 \mathrm{CP}$, que parecía apuntar hacia una naturaleza dogmática determinada: "Las consecuencias accesorias previstas en este artículo estarán orientadas a prevenir la continuidad en la actividad delictiva y los efectos

76 DE LA CUESTA ARZAMENDI, J.L.: “Personas jurídicas...”, cit., p. 970.

77 TIEDEMANN ("Responsabilidad penal...", cit., p. 98) consideraba que "presentan un atraso notable". Véase también DE LA CUESTA ARZAMENDI, J.L: "Responsabilidad penal...”, cit., p. 52; y FEIJOO SÁNCHEZ, B.J.: "El art. 129 como...", cit., pp. 301 y ss. DE LA CUESTA ARZAMENDI notaba ya, en la aplicación de estas consecuencias, "un excesivo arbitrio judicial" (DE LA CUESTA ARZAMENDI, J.L.: "Personas jurídicas, consecuencias accesorias...", cit., p. 972).

78 SILVA SÁNCHEZ escribía en 2006: "Lo cierto es que, si dejamos de lado el ámbito de la legislación contra el terrorismo y la criminalidad organizada, el balance de estos diez años de aplicación judicial de «consecuencias accesorias» es bastante elocuente: como se verá, la disolución de la sociedad, asociación o fundación no se ha acordado nunca; la intervención de la empresa, sólo en una ocasión. La consecuencia accesoria aplicada de modo general ha sido la clausura temporal de establecimientos. Pero la expresión «de modo general» significa aquí en «unas pocas resoluciones». El Tribunal Supremo no ha dictado ninguna sentencia en la que haya sentado doctrina extensa sobre el art. 129 CP. Los tribunales inferiores han mostrado, por lo demás, una prudencia extrema en la imposición de las consecuencias referidas" (SILVA SÁNCHEZ, J.M.: "La aplicación judicial de las consecuencias accesorias para las empresas", en Indret: Revista para el Análisis del Derecho, $\mathrm{N}^{\circ} .2$, 2006, p.4); aunque esta ineficacia no fuera mala necesariamente, a juicio de SILVA (SILVA SÁNCHEZ, J.M.: "La aplicación judicial...", cit., p. 12). 
de la misma" ${ }^{979}$. Pero ni con ello las consideraciones sobre su naturaleza dogmática eran unánimes y las inducciones teóricas tomaron itinerarios distintos ${ }^{80}$ : medidas de seguridad, penas, sanciones administrativas o ninguna de las anteriores ${ }^{81}$.

Actualmente, tras la modificación de 2010, las discusiones en torno a la naturaleza del art. $129 \mathrm{CP}$ quedan zanjadas, en opinión de BACIGALUPO, ya que "no pueden ser en el nuevo escenario más que penas en su más estricto sentido" $"$. Tal es así

79 MIR PUIG escribía en 2004 que "las «consecuencias accesorias» que el art. $129 \mathrm{CP}$ permite imponer sobre personas jurídicas o empresas tienen de común una naturaleza no punitiva, sino puramente preventiva" (MIR PUIG, S.: "Una tercera vía...", cit. p. 4). Las penas previstas en el art. 33.7 b) a g) tendrían, entonces, el fin de prevenir la continuidad delictiva (en este sentido, véase ZUGALDÍA ESPINAR, J.M., La responsabilidad criminal de las personas jurídicas..., cit. p. 131).

80 Véase una panorámica amplia en DE LA MATA BARRANCO, N.J. y HERNÁNDEZ DÍAZ, L.: "Los problemas de congruencia...,", cit., p. 242 (nota 24). También, DE LA CUESTA ARZAMENDI, J.L.: "Personas jurídicas, consecuencias accesorias...", cit., pp. 976 y ss.; en concreto, los trabajos anteriores a la reforma de GUARDIOLA LAGO, M.J.: Responsabilidad penal de las personas jurídicas y alcance del art. 129 del Código Penal, Valencia, 2004; DE LA FUENTE HONRUBIA, F.: Las consecuencias accesorias del art. 129 del Código Penal, Valladolid, 2004.

81 La necesidad de prevención encaja sin duda con la identidad entre consecuencias accesorias y medidas de seguridad, pero, como indica DE LA CUESTA, "Eminentes autores destacaron (...) la incompatibilidad entre el concepto de peligrosidad individual y la peligrosidad objetiva del art. 129.3, exclusiva de la persona jurídica y caracterizada por su nota instrumental (...) Para otros autores, las consecuencias accesorias debían considerarse propias y verdaderas penas, por rellenar los requisitos sustantivos propios de éstas y tratarse de respuestas a la comisión de un hecho delictivo (...) La mayor parte de los autores, apoyados en su 'naturaleza peculiar', acabaron inclinándose a favor de su configuración como una 'tercera vía' penal, distinta de la propia de las penas y de las medidas de seguridad". (DE LA CUESTA ARZAMENDI, J.L: "Responsabilidad penal...", cit., pp. 52-53) En el mismo sentido, FERNÁNDEZ TERUELO, J.: "Las consecuencias accesorias...", cit., p. 116).

82 BACIGALUPO SAGESSE, S.: "Los criterios de imputación...”, cit., p. 7. Una de las pocas resoluciones judiciales que aplican el art. 129 CP (STS 436/2012) impone el cierre de un local por tráfico de drogas. Indica la sentencia que esto se propone como una suerte de "tercera respuesta penal" que pretende "prevenir futuras acciones delictivas", por lo que podría persistir cierta fricción doctrinal. 
que las consecuencias accesorias del actual art. $129 \mathrm{CP}$ remiten directamente a las contempladas en el art. $33.7 \mathrm{c}$ ) a g) $\mathrm{CP}^{83}$, por lo que parecen integrarse entre las penas.

A pesar de un cambio tan radical en su literalidad, FARALDO CABANA indica que "de la nueva redacción del art. 129 CP no cabe esperar una mayor aplicación de las consecuencias accesorias, pues se mantienen los factores que dieron lugar a su práctica inaplicación de 1995 a 2010"\$4; y que siguen pasando, a nuestro juicio, por una ausencia de presupuestos de imputación que retraen a la judicatura en su aplicación ${ }^{85}$. Por este motivo, al margen de que quede apaciguado el debate sobre su naturaleza dogmática, lo cierto es que la dimensión pragmática del art. 129 CP persiste en su ineficacia, por lo que podemos concluir que de nada ha servido que la reforma legal anule el debate dogmático. Digamos, con las palabras de ATIENZA, que en este caso la dogmática no ha desarrollado su función como tecno-praxis. Más bien al contrario, esta función ha sido sosla-

83 Sobre las diferencias entre la redacción antes y después de la reforma por LO 5/2010, puede verse FEIJOO SÁNCHEZ, B.J.: "El art. 129 como complemento de la responsabilidad penal de las personas jurídicas", en BAJO FERNÁNDEZ, M., FEIJOO SÁNCHEZ, B.J. y GÓMEZ-JARA DÍEZ, C., Tratado de responsabilidad penal de las personas jurídicas: adaptado a la Ley 1/2015, de 30 de marzo, por la que se modifica el Código Penal, Cizur Menor, 2016, p. 303.

84 FARALDO CABANA, C.: "Algunos aspectos de la reforma penal: irresponsabilidad penal de la empresa por los delitos contra los derechos de los trabajadores. ¿Sigue siendo posible aplicar las consecuencias accesorias?", en Revista general de Derecho del trabajo y de la Seguridad Social, 34, 2013, p. 572.

85 Sobre la inaplicación de las consecuencias accesorias, antes y después de 2010, véase RAMÓN RIBAS, E.: La persona jurídica en el derecho penal. Responsabilidad civil y criminal de la empresa, Granada, 2009, pp. 231 y ss. También RAMÓN RIBAS, E.: "De las consecuencias accesorias", en MORALES PRATS, F. y QUINTERO OLIVARES, G. (coords.), Comentarios al Código penal español, Cizur Menor, 2016. En el mismo sentido, FEIJOO SÁNCHEZ, B.J.: "El art. 129 como complemento...”, cit., p. 302. FERNÁNDEZ TERUELO, J.: "Regulación vigente...”, cit., p. 60: la ausencia de "presupuestos claros llevó a una práctica inaplicación judicial" de las consecuencias accesorias. 
yada por el legislador, de tal manera que el resultado práctico ha sido evitar el debate.

\section{Retorno a la función preventiva del artículo 129 del Có- digo penal}

Con la introducción en 2015 de los sistemas de cumplimiento surge, en relación con su función en clave de culpabilidad que hemos expuesto, una posibilidad para redefinir el art. 129 CP. Y es que las consecuencias accesorias podrían desplegar desde esas elucubraciones dogmáticas nuevas derivaciones prácticas.

La ausencia de eficacia y efectividad del art. $129 \mathrm{CP}$ a la luz de una valoración ex post persiste después de su reforma en 2010, ya que nunca ha dejado de ser un precepto residual sin apenas aplicación, bien por ausencia de presupuestos claros de aplicación, bien por el desplazamiento causado por el art. 31bis CP. Este desplazamiento queda señalado por razón no ya de la naturaleza de la consecuencia jurídica, sino por razón de la naturaleza del ente colectivo a quien se le aplica: "La posibilidad de imponer sanciones penales a entidades discurre (...) bien por la aplicación de penas, bien por la de consecuencias accesorias, en función de que se trata de personas jurídicas o entes que carezcan de personalidad jurídica. La línea divisoria para conocer el régimen aplicable es, así, un criterio exclusivamente formal, como es el hecho de que la entidad tenga reconocida por el ordenamiento jurídico capacidad jurídica y capacidad de obrar" ${ }^{\prime 6}$. Queda desplazado, por tanto, cualquier criterio dogmático que distinga al art. 129 del 31 bis CP por sus fines o funciones, ya que incluso remiten a un elenco compartido, en parte, de pe-

86 GIL NOBAJAS, M.S.: "Personas jurídicas versus entidades sin personalidad jurídica: análisis y revisión de la dimensión institucional que delimita la aplicación de los artículos 31 bis y 129 del código penal", en Revista General de Derecho Penal, No 29, 2018, p. 3. En el mismo sentido, FEIJOO SÁNCHEZ, B.J.: "El art. 129 como complemento...”, cit., pp. 304 y ss. 
nas ${ }^{87}$. Esto es, la retribución de entes colectivos se bifurca en dos líneas por razón de la naturaleza de la persona jurídica. Pero sucede, como notábamos, que una de esas dos líneas no se aplica en absoluto. Esto, por tanto, implica un déficit de racionalidad legislativa ${ }^{88}$ que invita a una remodelación.

GIL NOBAJAS, siguiendo a GÓMEZ-JARA propone, a efectos de desterrar la ineficacia y el desajuste patentes del art. $129 \mathrm{CP}$, una nueva conceptuación del ente colectivo a efectos penales (reclamando la autonomía de lo penal) que agrupe tanto a las personas jurídicas como a otras entidades colectivas sin personalidad jurídica. Se trataría de "establecer un concepto autónomo de persona jurídica responsable penalmente, vinculado con la capacidad de afectación al bien jurídico"89.

De este modo, si hacemos que el guardagujas que rige la aplicación alternativa entre los artículos 31 bis y 129 CP sea su finalidad, el primero podría aplicarse sobre cualquier ente colectivo por la realización de un hecho culpable. El art.129 CP podría, entonces, o bien suprimirse, o bien ser dotado de nuevos presupuestos de aplicación ${ }^{90}$. En este segundo supuesto, y por esta espita abierta por GIL NOBAJAS, brota, entonces, la posibilidad de redefinir la función del art. 129 CP, así como unos presupuestos de aplicación acordes con ella. Nuestra propuesta

87 Las consecuencias accesorias, tras la reforma de 2010, prescinden de todo criterio de imputación, "tratando de modo desigual -sin que se acierte a comprender el porqué- las entidades con personalidad jurídica y las que no la tienen" (DE LA MATA BARRANCO, N.J. y HERNÁNDEZ DÍAZ, L.: "Los problemas de congruencia en la concreción y aplicación de las sanciones previstas para las personas jurídicas", en DE LA CUESTA ARZAMENDI, J.L. (dir.) y DE LA MATA BARRANCO, N.J. (coord.), Responsabilidad Penal de las Personas Jurídicas, Cizur Menor, 2013, p. 243).

88 Es evidente, en los términos expuestos, el déficit de racionalidad pragmática y jurídico formal, en términos de ATIENZA RODRÍGUEZ (Contribución a una teoría de la legislación, Madrid, 1997, pp. 32 y ss.). Véase también DÍEZ RIPOLLÉS, J.L.: La racionalidad de las leyes penales, Madrid, 2003, pp. 95-96.

89 GIL NOBAJAS, M.S.: "Personas jurídicas...", cit. p. 36

90 GIL NOBAJAS, M.S.: "Personas jurídicas...”, cit. pp. 34-35. 
pasaría por reivindicar, en parte, la vieja literalidad del precepto en relación con la evitación de delitos futuros, ya que aquel texto sí podría desplegar una eficacia indubitada en el nuevo paradigma de responsabilidad colectiva.

En este enredo entre la dogmática y la pragmática, la mayor parte de la doctrina descartaba la naturaleza del art.129 CP como medidas de seguridad en tanto que las personas jurídicas no podían ser sujetos activos de delitos $\mathrm{y}$, por tanto, no podían ser peligrosas en términos criminales ${ }^{91}$ (solo podían caracterizarse como instrumentos peligrosos, para los que no puede operar la función de las medidas de seguridad ${ }^{92}$ ). Si decae aquel obstáculo, como hemos tratado de argumentar supra, lo cierto es que resultaría plausible categorizar la naturaleza de las consecuencias accesorias como verdaderas medidas de seguridad.

91 Véase, sobre este asunto, FERNÁNDEZ TERUELO, J.: "Las consecuencias accesorias del art. 129 del Código penal frente a la delincuencia organizada", en PUENTE ABA, L., ZAPICO BARBEITO, M.H., y RODRÍGUEZ MORO, L. (coord.): Criminalidad organizada, terrorismo e inmigración: retos contemporáneos de la política criminal, Granada, 2008, p. 115. Desde cierto agudizamiento funcional, podríamos avalar la versión de las consecuencias accesorias, antes de la modificación de 2010, como una suerte de medida de seguridad que no exigía "ninguna activación por parte de la persona jurídica o empresa que la haga merecedora de la medida y sirva de medida de la gravedad de esta" (MIR PUIG, S.: "Una tercera vía en materia de responsabilidad penal de las personas jurídicas", en Revista Electrónica de Ciencia Penal y Criminología, n6, 2004, p. 4). Sin embargo, "al caracterizarse como consecuencias accesorias parecen presuponer la comisión de un delito por parte de una persona física, lo que puede impedir su imposición cuando serían más necesarias, esto es, cuando se desconocen los responsables físicos" (MIR PUIG, S.: "Una tercera vía...”, cit., p. 5).

92 La Propuesta Alternativa de Parte General presentada por el Grupo Parlamentario Comunista como enmienda a la totalidad del Proyecto de 1980 disponía lo siguiente, que hubiera circunvalado este atolladero dogmático: "No obstante, las medidas de seguridad especialmente previstas al efecto, podrán recaer sobre las personas o entidades jurídicas a causa de los delitos que sus directivos, mandatarios o miembros cometieron en el ejercicio de las actividades sociales o aprovechando la organización de tales entes, cuando pueda presumirse fundadamente que seguirán siendo utilizadas para la comisión de delitos" (cit. en MIR PUIG, S.: "Una tercera vía...", cit., p. 3). 
Decía en 2004 MIR PUIG que, "del mismo modo que para personas físicas peligrosas no están sujetas al principio de culpabilidad porque no suponen una reprobación ético-jurídica del sujeto, tampoco unas medidas puramente preventivas basadas únicamente en la peligrosidad objetiva de la persona jurídica o la empresa tienen por qué requerir la culpabilidad de éstas, puesto que tampoco implican ningún sentido de reproche dirigido a las mismas" ${ }^{\prime 93}$. Y esta lógica puede sustentar la proyección del art. 129 CP como medidas de seguridad, basadas, eso sí, en un hecho antijurídico propio de la persona jurídica, pero sin culpabilidad por su parte al haber implementado un sistema de cumplimiento eficaz, a priori, frente a la hipotética comisión del hecho cometido.

De este modo, retomando a MIR PUIG, podríamos decir que "es coherente la admisión de una modalidad especial de medidas preventivas para personas jurídicas y empresas objetivamente peligrosas que tampoco pueden ser culpadas"; una modalidad de medidas que "no implican el reproche ético-social que caracteriza a la pena" ". En el actual escenario, tras la reforma de 2015 , lo relevante es que esa modalidad de medidas preventivas ya no sería tan especial, sino que encajaría relativamente bien con la dogmática general sobre medidas de seguridad (más allá de que queden sistematizadas, aparte, en el art.129 CP).

\section{Medidas de seguridad para personas colectivas peligrosas}

El art. 6.1 CP prevé la posibilidad de imponer medidas de seguridad a aquellos sujetos que sean peligrosos, no solo en casos de eximente completa, sino también incompleta. Para que se puedan imponer estas medidas de seguridad es necesario que se cumpla el concepto de peligrosidad previsto legalmente en el art. 95.1 CP, donde se recogen dos elementos que deben darse de modo concurrente: "que el sujeto haya cometido un hecho

93 MIR PUIG, S.: "Una tercera vía...", cit. p. 12.

94 MIR PUIG, S.: "Una tercera vía...”, cit. p. 14. 
previsto como delito", y "que del hecho y de las circunstancias personales del sujeto pueda deducirse un pronóstico de comportamiento futuro que revele la probabilidad de comisión de nuevos delitos".

Dice FRISCH que, "a diferencia de una pena pensada como mal que retribuye el hecho y orientada a la medida de culpabilidad, en las medidas de seguridad lo que está en el centro no es el hecho, sino el estado del autor, su peligrosidad o necesidad de tratamiento"95. La aplicación de esta fórmula a personas físicas, como es evidente, debe ponderarse y limitarse, de modo que no queden afectados otros derechos fundamentales del individuo. Sin embargo, su aplicación a los entes colectivos sería menos espinosa, ya que la naturaleza de estos entes pasa necesariamente por cierta instrumentalidad que hace que los riesgos de afectación a otras dimensiones de la empresa sean relativamente marginales (sin minusvalorar la afectación a terceros dependientes de la empresa).

De este modo, indirectamente, las críticas vertidas contra la idoneidad de las sanciones previstas para las personas jurídicas nos pueden conducir hacia la idoneidad de las medidas de seguridad. En concreto, BAUCELLS LLADÓS defiende la necesidad de apuntar las sanciones hacia una finalidad preventiva especial. Y esto debe ser así porque el componente retributivo que incorporarían las penas no coadyuvaría a la resocialización entendida en el plano económico como el desarrollo de la actividad sin cometer hechos delictivos ${ }^{96}$. Las medidas de seguridad sobre personas jurídicas (o entes colectivos, en general) mantendrían en el quicio de la prevención especial el mal proyectado sobre la empresa no culpable, de modo que podrían esquivarse

95 FRISCH, W.: "Las medidas de corrección y seguridad en el sistema de consecuencias jurídicas del Derecho penal. Clasificación en las teorías de la pena, configuración material y exigencias en el Estado de Derecho", en Indret: Revista para el Análisis del Derecho, № 3, 2007, p. 5.

96 BAUCELLS LLADÓS, J.: "Las penas previstas para la persona jurídica en la reforma penal de 2010: un análisis crítico", en Estudios Penales y Criminológicos, 2013, p. 182. 
las situaciones que, contra la economía, pudieran derivar de la aplicación de otras consecuencias jurídicas.

En concreto, la previsión actual remite las consecuencias accesorias al catálogo de penas, aunque solo las recogidas en el art. $33.7 \mathrm{c})$ a g):

c) Suspensión de sus actividades por un plazo que no podrá exceder de cinco años

d) Clausura de sus locales y establecimientos por un plazo que no podrá exceder de cinco años.

e) Prohibición de realizar en el futuro las actividades en cuyo ejercicio se haya cometido, favorecido o encubierto el delito. Esta prohibición podrá ser temporal o definitiva. Si fuere temporal, el plazo no podrá exceder de quince años.

f) Inhabilitación para obtener subvenciones y ayudas públicas, para contratar con el sector público y para gozar de beneficios e incentivos fiscales o de la Seguridad Social, por un plazo que no podrá exceder de quince años.

g) Intervención judicial para salvaguardar los derechos de los trabajadores o de los acreedores por el tiempo que se estime necesario, que no podrá exceder de cinco años.

Estas previsiones parecen encajar en el fin preventivo especial que se le supone a las medidas de seguridad. Sucede, por tanto, que la división penológica propuesta por el legislador apunta a una diferenciación por fines de la consecuencia jurídica que invita a reformular las letras c) a g) como medidas de seguridad con fin preventivo. Mientras que, por otro lado, las sanciones previstas en las letras a) y b) (multa y disolución de la persona jurídica), no parece que puedan sacudirse un importante componente retributivo en sus fines, lo que las haría inhábiles como medidas de seguridad.

Esta lógica transcurre paralela a la racionalidad políticocriminal de las penas para personas jurídicas culpables de delitos. Esto es, cabe un debate sobre la idoneidad o no de la pena de multa o de la disolución de la empresa para interferir en los 
procesos de decisión de las personas jurídicas imputables; cabe un debate sobre la afectación a "terceros inocentes". Sin embargo, en relación con las medidas de seguridad para inimputables, este debate quedaría desactivado, ya que la propia naturaleza de las medidas de seguridad debería evitar todo componente retributivo. Porque, en esta línea, no importa la (in)capacidad de los entes colectivos para sufrir el mal, ya que no se pretende ni se contempla ${ }^{97}$.

Y abordar el debate sobre la idoneidad de las sanciones a las personas jurídicas en esta clave disociativa de consecuencias puede ser provechoso. Esto es, las penas previstas para los entes colectivos culpables podrían incorporar el castigo retributivo. En todo caso, el inciso del art. 66bis. $1^{\mathrm{a}} \mathrm{b}$ ) prevé que para la imposición y extensión de la pena deben tenerse en cuenta "sus consecuencias económicas y sociales, y especialmente los efectos para los trabajadores". Esto desvela, de nuevo, la tendencia dogmática de estas penas hacia las medidas de seguridad, que es el fundamento teórico desde el que mejor se desarrollarían estas consecuencias $^{98}$. Como dice FRISCH, "es especialmente super-

97 "Sentir el dolor de la sanción" ya tampoco se contempla en la legitimidad de la pena, como indica FARALDO CABANA (“¿Es la multa una pena apropiada para las personas jurídicas?", en DE LA CUESTA ARZAMENDI, J.L., PÉREZ MACHÍO, A.I. y UGARTEMENDÍA ECEIZABARRENA, J.I. (dirs.), Armonización penal en Europa, 2013, p. 108); pero no por ello se descarta como componente posible de la misma, mientras que sí debe quedar al margen de la medida de seguridad que, a lo sumo, sería "un mal no intencionado (...) por reflejo" (FRISCH, W.: "Las medidas de corrección...", cit., p. 16).

98 Esto, efectivamente, afecta a terceros. Pero este argumento solo podría admitirse si se admite igualmente en relación con las penas para personas físicas. FARALDO CABANA (“¿Es la multa una pena apropiada...?”, cit., p. 87) observa que "los costes que se han de considerar son aquellos que superan de forma notoria la normal afectación a terceros que es propia de cualquier pena". Por tanto, este podría ser otro criterio que clasifique aquellas consecuencias entre las medidas, y no entre las penas, sin perjuicio de que, como nota FRISCH ("Las medidas de corrección...", cit., p. 17), "las diferencias entre ambos institutos han disminuido. Pero esto no se relaciona con deficiencias conceptuales de las medidas, sino con una constante modificación de la pena en dirección a un acogimiento (limitado) de las ideas de la prevención especial". 
ficial aquella argumentación que cree poder deducir, a partir de los contenidos de prevención especial que ya tiene la pena sin más, la capacidad total del concepto de prevención especial"99. Esto es, sigue existiendo espacio legitimador de la disociación de consecuencias que refine la praxis de la prevención especial a través de otras medidas distintas de la pena. Además, el mal que, vehiculizado en las empresas, pudiera repercutir en la economía, no sería tal, ya que las empresas sin cultura de cumplimiento serían, en el largo plazo, nocivas para la economía. Sin embargo, las empresas que no puedan ser culpables en relación con determinados delitos no deberían ser castigadas, sino controladas preventivamente para evitar volver a causar el mal concreto ya causado.

Una reordenación pragmática de las anteriores líneas argumentales la propone el propio Código penal en su art. 66 bis $1^{\text {a }}$, ya que diferencia las consecuencias catalogables como accesorias (además de la disolución) de la multa como principal consecuencia jurídica que puede funcionar exclusivamente como pena. Así, para las consecuencias previstas en el art. 33.7 b) a g) $\mathrm{CP}$, el art. 66 bis $1^{\text {a }} \mathrm{CP}$ dispone que habrá de tenerse en cuenta "su necesidad para prevenir la continuidad de la actividad delictiva o de sus efectos". Esto es, las reglas de determinación de la pena conservan el fin de la prevención especial, como un horizonte necesario, pero de esquiva aplicación.

De esta clasificación se deriva que esas penas que, hoy en día, están previstas con el fin de prevención de la actividad delictiva, podrían transformarse en medidas de seguridad; porque ese sería su mejor encaje dogmático ${ }^{100}$. En este sentido, pue-

99 FRISCH, W.: "Las medidas de corrección...", cit., p. 18.

100 Así, en el contexto de los entes colectivos, decaería una de las principales críticas frente a las medidas de seguridad que indica FRISCH ("Las medidas de corrección...", cit., p. 12): "son ejecutadas en establecimientos muy similares"; también podría esquivar la principal de las dificultades en la valoración de su ejecución: "la posibilidad de formular pronósticos" (FRISCH, W.: "Las medidas de corrección...", cit., p. 10), ya que estos pronósticos se vincularían al análisis de eficacia ex post del protocolo de prevención en relación con el hecho antijurídico cometido. 
de argumentarse que el componente preventivo especial de la pena de multa es cuestionable, por lo que esta consecuencia solo podría funcionar como pena en sentido clásico ${ }^{101}$. Más aún, la imposición de "la pena de multa es generalmente de aplicación obligatoria, siendo el resto de penas de aplicación potestativa. De esta forma, el juicio de necesidad de la pena de multa ha sido realizado por el legislador, mientras que el del resto de las penas, por delegación de aquél, debe ser llevado a cabo por el Juez o Tribunal al analizar cada caso"102. De esto también se colige que la imposición de las consecuencias potestativas (esas en las que el juez debe analizar la peligrosidad) encajan con mucha más precisión en la naturaleza dogmática de las medidas de seguridad.

Por otro lado, la pena de multa (a la que, probablemente, habría que añadir, por su carácter definitivo, la disolución) seguiría incorporando el fin retributivo y se impondría de acuerdo con un juicio sobre el hecho, de modo que quedaría como la genuina pena para personas jurídicas culpables.

Debe notarse, además, que la aplicación de las medidas de seguridad sería mucho más flexible que la imposición de las penas a las personas jurídicas (o entes colectivos) culpables. Como indica FARALDO CABANA, "si la entidad presentaba peligrosidad subjetiva en el momento de la comisión del delito, pero posteriormente ha adoptado medidas idóneas para elimi-

101 "Desde la perspectiva del análisis económico del Derecho, se parte de un modelo en el que las personas toman decisiones racionales en la medida en que hacen elecciones que tienden a maximizar sus beneficios y minimizar sus costes” (FARALDO CABANA, P.: “¿Es la multa una pena apropiada...?”, cit., p. 98); sin embargo, “dado que la persona jurídica es distinta de las personas físicas que la dirigen, tampoco está claro si una multa elevada, pero de la que es destinataria la persona jurídica, tiene efectos disuasivos” (FARALDO CABANA P.: “Es la multa una pena apropiada...?”, cit., p. 102).

102 FARALDO CABANA, P.: “¿Es la multa una pena apropiada...?”, cit., p. 97. Esta misma interpretación sobre las consecuencias accesorias, puede verse en RAMÓN RIBAS, La persona jurídica en el derecho penal. Responsabilidad civil y criminal de la empresa, Granada, 2009, p. 255 
narla o reducirla, el juicio de peligrosidad decae"103. Esta valoración (que FARALDO realiza sobre algunas de las actuales penas conforme a la previsión del art. 66bis $1^{\mathrm{a}}$ a), en nuestra lógica, implicaría que dejase de aplicarse la medida de seguridad en caso de remisión de la peligrosidad, por expresión concreta del Código, así como por adecuación dogmática.

El desplazamiento literal en el Código penal, por tanto, llevaría a extraer las consecuencias del art. 33.7 c) a g) del catálogo de penas y que, vehiculizadas en el art. $129 \mathrm{CP}$, pasasen a ser medidas de seguridad para entes colectivos inimputables o semiimputables. Quedarían, por tanto, como penas para los entes colectivos las de la multa y la disolución ${ }^{104}$.

Con esta lógica legal, el debate sobre la idoneidad de las consecuencias aplicables a personas jurídicas podría solucionarse, en términos fácticos, si se logra una situación relativamente estable en la que las empresas incorporen protocolos de prevención de delitos por sistema $\mathrm{y}$, por tanto, solo estén expuestas a medidas de seguridad que eviten la retribución. Debe añadirse a esto que, impuesta una medida de seguridad, esta dejaría de aplicarse cuando la empresa incorporase las correcciones debidas al sistema de cumplimiento según carencias detectadas ex post, ya que en ese momento decaería su peligrosidad subjetiva en relación con el hecho antijurídico cometido. Esta estrategia animaría a un efectivo y progresivo perfeccionamiento de los sistemas de

103 FARALDO CABANA, P.: “¿Es la multa una pena apropiada...?”, cit., p. 86.

104 Cabría, de hecho, la misma articulación penológica actual, dejando espacio a la implementación de las medidas de seguridad según las reglas de la inimputabilidad previstas para los tres primeros números del art.20 CP en relación con el art.21.1 CP. Esto es, si el compliance es eficaz a priori, la persona jurídica quedará exenta de pena, pero expuesta a la imposición de medidas (letras c a g del art. 33.7 CP). Si solo puede verificarse la "acreditación parcial” del sistema de cumplimiento (según la letra del art.31bis), se valorará la atenuación de la pena (la multa) y cabría la imposición de medidas de seguridad por semiimputabilidad (y esto sería coherente con lo previsto por el art.21.1CP, que prevé que, si no concurren todos los requisitos necesarios para eximir de responsabilidad, se aplicará una atenuante). 
cumplimiento a través de una estrategia acorde con los criterios dogmáticos que rigen nuestro sistema penal ${ }^{105}$.

\section{Excurso}

Estas hipótesis de reordenación dogmática de las consecuencias jurídicas aplicables a entes colectivos podrían quedar mejor apuntaladas si, circunvalando por un momento el sendero dogmático seguido hasta aquí, damos por buena la teoría de la ruptura del concepto unitario de injusto que propone SILVA SÁNCHEZ ${ }^{106}$ (específicamente, para nuestra variante, en relación con los entes colectivos).

Indica SILVA que "el criterio rector del concepto dominante de injusto continúa siendo la dañosidad o lesividad social"107. Sin embargo, la propuesta del autor pasa por reconocer el injusto de modo fragmentado en la parte objetiva y subjetiva del tipo, y aun en la culpabilidad, de modo que "el injusto no culpable es menos injusto que el injusto culpable"108. De este modo, la teoría de SILVA apuesta por un concepto de injusto fundamentado en una antinormatividad no secuenciada cronológicamente, sino sincrónicamente. Esto es, el injusto reside en cada elemento de tipicidad o culpabilidad, sin que deba observarse un escalonamiento en el que cada peldaño es presupuesto necesario del siguiente a efectos de alguna respuesta penal. En esta lógica, ni siquiera la ausencia de acción impediría una intervención del sistema penal en forma de medida de seguridad. El resultado y la peligrosidad pueden bastar para legitimar esas

105 Vale aquí la insuficiencia que señala ZUGALDÍA ESPINAR, quien echa de menos "medidas específicas para eliminar las consecuencias de la infracción que ha originado la responsabilidad" (ZUGALDÍA ESPINAR, J.M. "Societas delinquere potest...", cit., p.10).

106 SILVA SÁNCHEZ, J.M.: “¿Adiós a un concepto unitario de injusto en la teoría del delito? A la vez, una breve contribución a la teoría de las medidas de seguridad", en Indret: Revista para el Análisis del Derecho, No. 3, 2014

107 SILVA SÁNCHEZ, J.M.: “¿Adiós a un concepto unitario...?”, cit., p. 2.

108 SILVA SÁNCHEZ, J.M.: “¿Adiós a un concepto unitario...?”, cit., p. 3. 
medidas, en tanto que así se desarrollaría la función preventivo especial equivalente a medidas policiales ${ }^{109}$.

No cabe duda de la acogida doctrinal desigual de estas medidas sobre las personas físicas. Pero, ¿por qué esas especulaciones nos resultan útiles? Porque, en las personas físicas, el proceso cognitivo, volitivo y ejecutivo guarda una cierta secuenciación figurativa que sería refractario a una ruptura tan funcionalista del injusto. Sin embargo, en relación con los entes colectivos (y según lo expresado supra más en concreto sobre la ontología de la empresa), la secuenciación cronológica de los hechos delictivos queda diluida y, por tanto, cabe una valoración del injusto según cierta sincronía del hacer/ser empresarial. Y esta sincronía del hecho delictivo admitiría mejor esta propuesta axiológica de SILVA sobre elementos que, sin relación acumulativa, podrían legitimar de manera independiente -valorada la peligrosidad subjetiva- la imposición de medidas de seguridad. Esto nos llevaría a hacer tender las consecuencias jurídicas imponibles a las empresas hacia las medidas de seguridad, ya que son, según lo expuesto, la estrategia más adecuada a los objetivos político-criminales perseguidos desde el inicio.

\section{Epílogo: apertura al campo criminológico de la peligrosi- dad empresarial}

Decíamos al inicio que tomamos la dogmática como un conjunto de nociones sobre el que construir soluciones jurídicas operativas en un doble sentido: por un lado, que resuelvan problemas y contradicciones; por otro lado, que permanezcan en un quicio de previsibilidad y comprensión comunicativa.

En estas líneas, hemos intentado localizar un problema concreto: con la implantación de los protocolos de cumplimien-

109 Cabe esta lectura sin perjuicio de que las medidas de seguridad desplieguen, a su vez, una función simbólica, preventivo general positiva, indisoluble a la acción del Derecho penal como sistema (SILVA SÁNCHEZ, J.M.: “¿Adiós a un concepto unitario...?", cit., p. 15). 
to en 2015, se puede reconocer en el plano teórico un conjunto de empresas que, al contar con un compliance eficaz a priori, no respondan ante el sistema penal, independientemente del daño causado. Esto es perturbador porque, en tal caso, se podría estar produciendo un tratamiento mucho más favorable a las personas jurídicas que a las personas físicas, aunque todas queden, en teoría, bajo una misma influencia dogmática.

Una hipótesis resolutiva de este problema, que hemos expuesto en sus términos esenciales, pasa por considerar que los protocolos de cumplimiento señalan el itinerario de la inimputabilidad de las personas jurídicas. En esta lógica, las personas jurídicas que cometen hechos típicos y antijurídicos deberían estar expuestas a las mismas consecuencias (estirando las mismas implicaciones dogmáticas) que las personas físicas que cometen hechos típicos y antijurídicos, aun sin ser culpables.

Fijado este encaje en la teoría del delito, el sistema penal debería atender al elemento de la peligrosidad en relación con el daño causado y la probabilidad de que pueda volver a causarse. En este sentido, se recoge en el art. 6.1 CP la posibilidad de imponer medidas de seguridad a los sujetos peligrosos, tanto en supuestos de eximente completa como incompleta. Para que se puedan imponer estas medidas de seguridad es necesario verificar el concepto de peligrosidad previsto legalmente en el art. 95.1 CP, que exige dos elementos de modo concurrente: "que el sujeto haya cometido un hecho previsto como delito", y "que del hecho y de las circunstancias personales del sujeto pueda deducirse un pronóstico de comportamiento futuro que revele la probabilidad de comisión de nuevos delitos".

El abordaje legislativo actual remite la solución de esta tesitura a una aplicación alternativa entre el art. 31bis CP y el art. $129 \mathrm{CP}$, donde este último se aplica a entes colectivos sin personalidad jurídica. De estas previsiones, resulta, en la práctica, que el art. 31bis CP no atiende la dimensión de peligrosidad de las personas jurídicas no culpables y que el art. $129 \mathrm{CP}$, que no se aplica apenas, no puede aplicarse a personas jurídicas. Identi- 
ficamos, con ello, un evidente déficit de racionalidad pragmática -por inaplicación del precepto- y sistemática -por una coexistencia enmarañada de ambos preceptos que remiten a un mismo catálogo de penas-.

Así, el art. 66bis $1^{\text {a }} \mathrm{CP}$ prevé el condicionamiento de la imposición de ciertas penas a personas jurídicas a "su necesidad para prevenir la continuidad de la actividad delictiva". Y, como veíamos, la modificada redacción del art. 129 CP preveía el fin de la prevención en la imposición de consecuencias accesorias. Con el actual panorama de responsabilidad de las personas jurídicas, cabría una reordenación de la vigente lógica deshilachada de consecuencias jurídicas aplicables a entes colectivos: si, actualmente, la aplicación alternativa de los artículos 31 bis y 129 CP pasa por la naturaleza del ente colectivo, de lege ferenda podría pasar por diferenciar sus fines como penas (31bis CP) o como medidas de seguridad (129 CP). Por tanto, a los entes colectivos con personalidad jurídica (capaces de incorporar un compliance) podría aplicárseles una pena, vía art.31bis $\mathrm{CP}$, o una medida de seguridad, vía art.129 CP. A los entes colectivos sin personalidad jurídica (incapaces de incorporar un compliance) no podría aplicárseles una medida de seguridad, ya que siempre resultarían culpables por vía del art.31bis CP.

Nuestra propuesta, en concreto, mantendría como genuinas penas para los entes colectivos (con o sin personalidad jurídica) las multas y la disolución. El art.33.7 CP, por tanto, podría limitarse, para recoger lo aquí expuesto, a las dos primeras letras de su enunciado.

Nuestra propuesta conceptuaría, por otro lado, como medidas de seguridad para entes colectivos (en la práctica, para personas jurídicas) la suspensión de actividades, la clausura de locales, la prohibición de realizar actividades, la inhabilitación para obtener subvenciones y la intervención judicial. Así, la integración en el Libro I de nuestro Código penal aconsejaría alojar estas medidas en el capítulo I del Título IV, De las medidas de seguridad (en un hipotético artículo $96.3 \mathrm{CP}$ ). Se trataría, en 
su caso, de medidas que dejarían de aplicarse cuando la empresa dejase de ser peligrosa, situación que pasa, necesaria pero no únicamente, por la corrección de sus protocolos de prevención de delitos según un análisis de su eficacia post-delictiva.

Para aplicar, con esta lógica de lege ferenda, las penas del art.33.7 CP o las medidas de seguridad del hipotético art.96.3 $\mathrm{CP}$, sería necesario que el art. 31 bis CP sustituya la expresión "personas jurídicas" por el de "entes colectivos"; y, paralelamente, el art.129 CP también debería referir "entes colectivos", en general, en lugar de tan solo a los entes colectivos excluidos del art.31bis CP, así como recoger la regla de aplicación ahora prevista para las penas en el art.66bis $1^{\mathrm{a}}$ a) $\mathrm{CP}$ : "prevenir la continuidad de la actividad delictiva o de sus efectos".

Esto llevaría a que los tribunales comenzasen a dar cuerpo al concepto de peligrosidad empresarial, ya que este sería central en la gestión penal de los daños sociales causados por empresas. Las medidas de seguridad para entes colectivos conformarían, entonces, un tratamiento penal integral de los delitos cometidos por empresas; medidas informadas tanto por razones funcionales como de integración dogmática en un sistema punitivo que los entes colectivos comparten con las personas físicas.

\section{Bibliografía}

ABIA GONZÁLEZ, R. y DORADO HERRANZ, G.: Implantación práctica de un sistema de gestión de cumplimiento - compliance management system, Cizur Menor, 2017

ATIENZA RODRÍGUEZ, M.: "La dogmática jurídica como tecno-praxis", en CARBONELL SÁNCHEZ, M., FIX FIERRO, H. y VALADÉS, D., Estado constitucional, derechos humanos, justicia y vida universitaria. Estudios en homenaje a Jorge Carpizo, tomo IV, México, 2015, pp. 169-196

ATIENZA RODRÍGUEZ, M.: Contribución a una teoría de la legislación, Madrid, 1997 
BACIGALUPO SAGESSE, S., "Los criterios de imputación de la responsabilidad penal de los entes colectivos y de sus órganos de gobierno (arts. 31 bis y 129 CP)", en Diario La Ley, $\mathrm{n}^{\circ} 7541,2011$, pp. 1-14

BAJO FERNÁNDEZ, M.: "Vigencia de la RPPJ en el derecho sancionador español", en BAJO FERNÁNDEZ, M., FEIJOO SÁNCHEZ, B. J. Y GÓMEZ-JARA DÍEZ, C.: Tratado de responsabilidad penal de las personas jurídicas: adaptado a la Ley 1/2015, de 30 de marzo, por la que se modifica el Código Penal, Cizur Menor, 2016, pp. 25-54

BAUCELLS LLADÓS, J.: "Las penas previstas para la persona jurídica en la reforma penal de 2010: un análisis crítico", en Estudios Penales y Criminológicos, 2013, pp. 175-218

CARBONELL MATEU, J.C.: "Responsabilidad penal de las personas jurídicas. Reflexiones en torno a su "dogmática" y al sistema de la reforma de 2010", en Cuadernos de política criminal, $\mathrm{N}^{\mathrm{o}}$ 101, 2010, pp. 5-33. https://doi. org/10.4067/S0718-33992010000100005

CASANUEVA SANZ, I.: La imputabilidad, el consumo de drogas y su regulación jurídico-penal. una revisión desde las ciencias de la salud (Tesis doctoral), Bilbao, 2013

DE LA CUESTA ARZAMENDI, J.L.: "Personas jurídicas, consecuencias accesorias y responsabilidad penal", en ARROYO ZAPATERO, L. y BERDUGO GÓMEZ DE LA TORRE, I. (coords.), Homenaje al Dr. Marino Barbero Santos: "in memorian”, Vol. 1, 2001, pp. 967-992

DE LA CUESTA ARZAMENDI, J.L: "Responsabilidad penal de las personas jurídicas en el Derecho español", en DE LA CUESTA ARZAMENDI, J.L. (dir.) y DE LA MATA BARRANCO, N.J. (coord.), Responsabilidad Penal de las Personas Jurídicas, Cizur Menor, 2013, pp. 49-102

DE LA CUESTA ARZAMENDI, J.L: "Responsabilidad penal de las personas jurídicas en el Derecho español",

DE LA MATA BARRANCO, N.J.: "La actuación conforme a protocolos de prevención de delitos como causa de exención de responsabilidad penal", en DE LA CUESTA AR- 
ZAMENDI, J.L. (dir.) y DE LA MATA BARRANCO, N.J. (coord.), Responsabilidad Penal de las Personas Jurídicas, Cizur Menor, 2013, pp. 249-266

DÍEZ RIPOLLÉS, J.L.: La racionalidad de las leyes penales, Madrid, 2003

DURKHEIM, E.: De la división del trabajo social, trad. David Maldavsky, Buenos Aires, (1893) 1967

FARALDO CABANA, C.: "Algunos aspectos de la reforma penal: irresponsabilidad penal de la empresa por los delitos contra los derechos de los trabajadores. ¿Sigue siendo posible aplicar las consecuencias accesorias?", en Revista general de Derecho del trabajo y de la Seguridad Social, 34, 2013, pp. 555-576

FARALDO CABANA, P.: “¿Es la multa una pena apropiada para las personas jurídicas?”, en DE LA CUESTA ARZAMENDI, J.L., PÉREZ MACHÍO, A.I. y UGARTEMENDÍA ECEIZABARRENA, J.I. (dirs.), Armonización penal en Europa, 2013, pp. 77-113

FARALDO CABANA, P.: "Acerca de la idoneidad de la sanción pecuniaria para personas jurídicas: Una reflexión de Derecho español con apuntes de Derecho italiano", en PUENTE ABA, L.M. (ed.), Economía y Derecho penal en Europa: una comparación entre las experiencias italiana y española. Actas del Congreso hispano-italiano de Derecho penal económico. Universitá degli Studi di Milano, 29-30 de mayo de 2014, A Coruña, 2015, pp. 251271. https://doi.org/10.17979/spudc. 9788497497329.251

FARALDO CABANA, P.: "La transmisibilidad de la pena de multa en las modificaciones estructurales. Sobre la aplicación del principio de personalidad de las penas a las personas jurídicas", en MORALES PRATS, F., TAMARIT SUMALLA, J.M. y GARCÍA ALBERO, R. (coord.), Represión penal y estado de derecho: homenaje al profesor Gonzalo Quintero Olivares, Cizur Menor, 2018, pp. 515-529

FEIJOO SÁNCHEZ, B.J.: "La persona jurídica como sujeto de imputación jurídico-penal”, en BAJO FERNÁNDEZ, 
M., FEIJOO SÁNCHEZ, B.J. y GÓMEZ-JARA DÍEZ, C., Tratado de responsabilidad penal de las personas jurídicas: adaptado a la Ley 1/2015, de 30 de marzo, por la que se modifica el Código Penal, Cizur Menor, 2016, pp. 49-64

FEIJOO SÁNCHEZ, B.J.: "Las características básicas de la responsabilidad penal de las personas jurídicas en el Código penal español", en BAJO FERNÁNDEZ, M., FEIJOO SÁNCHEZ, B.J. y GÓMEZ-JARA DÍEZ, C., Tratado de responsabilidad penal de las personas jurídicas: adaptado a la Ley 1/2015, de 30 de marzo, por la que se modifica el Código Penal, Cizur Menor, 2016, pp. 67-73

FEIJOO SÁNCHEZ, B.J.: "La extinción de la responsabilidad penal de las personas jurídicas", en BAJO FERNÁNDEZ, M., FEIJOO SÁNCHEZ, B.J. y GÓMEZ-JARA DÍEZ, C., Tratado de responsabilidad penal de las personas jurídicas: adaptado a la Ley 1/2015, de 30 de marzo, por la que se modifica el Código Penal, Cizur Menor, 2016, pp. 261-264

FEIJOO SÁNCHEZ, B.J.: "El art. 129 como complemento de la responsabilidad penal de las personas jurídicas", en BAJO FERNÁNDEZ, M., FEIJOO SÁNCHEZ, B.J. y GÓMEZ-JARA DÍEZ, C., Tratado de responsabilidad penal de las personas jurídicas: adaptado a la Ley 1/2015, de 30 de marzo, por la que se modifica el Código Penal, Cizur Menor, 2016, pp. 301-311

FERNÁNDEZ TERUELO, J.: "Las consecuencias accesorias del art. 129 del Código penal frente a la delincuencia organizada", en PUENTE ABA, L., ZAPICO BARBEITO, M.H., y RODRÍGUEZ MORO, L. (coord.), Criminalidad organizada, terrorismo e inmigración: retos contemporáneos de la política criminal, Granada, 2008, pp. 107-134

FERNÁNDEZ TERUELO, J.: "Regulación vigente: exigencias legales que permiten la atribución de responsabilidad penal a la persona jurídica y estructura de imputación: 
art.31 bis 1, art.31 ter y art.31 quinquies", en Responsabilidad penal y procesal de las personas jurídicas, Memento experto, Madrid, 2015, pp. 59-85

FERNÁNDEZ TERUELO, J.: "Responsabilidad penal de las personas jurídicas: el contenido de las obligaciones de supervisión, organización, vigilancia y control referidas en el art. 31 bis 1. b) del Código Penal español", en Revista electrónica de ciencia penal y criminología, $\mathrm{n}^{0}$ 21, 2019

FRISCH, W.: "Las medidas de corrección y seguridad en el sistema de consecuencias jurídicas del Derecho penal. Clasificación en las teorías de la pena, configuración material y exigencias en el Estado de Derecho", en Indret: Revista para el Análisis del Derecho, $\mathrm{N}^{\circ} 3,2007$, pp. 1-52

DE LA FUENTE HONRUBIA, F.: Las consecuencias accesorias del art. 129 del Código Penal, Valladolid, 2004

GIL NOBAJAS, M.S.: "Personas jurídicas versus entidades sin personalidad jurídica: análisis y revisión de la dimensión institucional que delimita la aplicación de los artículos 31 bis y 129 del código penal", en Revista General de Derecho Penal, No 29, 2018, pp. 1-44

GÓMEZ-JARA DÍEZ, C.: “Autoorganización empresarial y autorresponsabilidad empresarial. Hacia una verdadera responsabilidad penal de las personas jurídicas", en Revista electrónica de ciencia penal y criminología, No 8, 2006, pp. $1-27$

GÓMEZ-JARA DÍEZ, C.: "La culpabilidad de la persona jurídica”, en BAJO FERNÁNDEZ, M., FEIJOO SÁNCHEZ, B.J. y GÓMEZ-JARA DÍEZ, C., Tratado de responsabilidad penal de las personas jurídicas: adaptado a la Ley 1/2015, de 30 de marzo, por la que se modifica el Código Penal, Cizur Menor, 2016, pp. 143-220

GÓMEZ TOMILLO, M.: "Los distintos modelos de imputación de responsabilidad a las personas jurídicas: sistema español. Antecedentes", en Responsabilidad penal y procesal de las personas jurídicas, Memento experto, Madrid, 2015, pp. 39-58 
GUARDIOLA LAGO, M.J.: Responsabilidad penal de las personas jurídicas y alcance del art. 129 del Código Penal, Valencia, 2004

HARRIS, R.: "The Bubble Act: Its Passage and Its Effects on Business Organization", en The Journal of Economic History, vol. 54, n⿳3 3, 1994, pp. 610-627. https://doi. org/10.1017/S0022050700015059

HERNÁNDEZ DÍAZ, L.: "El nuevo artículo 31 bis del Código penal: exigencias legales (explícitas e implícitas) que permiten la atribución de responsabilidad penal a la persona jurídica”, en DE LA CUESTA ARZAMENDI, J.L. (dir.) y DE LA MATA BARRANCO, N.J. (coord.), Responsabilidad Penal de las Personas Jurídicas, Cizur Menor, 2013, pp. 103-125

HERNÁNDEZ GIL, A.: "Introducción al estudio del estructuralismo y el derecho", en HERNÁNDEZ GIL, A., NÚÑEZ LADEVÉZE, L., SOBRADO CHAVES, J.J. [et al.], Estructuralismo y Derecho, Madrid, 1973, pp. 11-52

HIGUERA GUIMERÁ, J.F.: "La prueba pericial psiquiátrica en los procedimientos judiciales penales y la medicina forense en España. Una respetuosa llamada "urgente" de atención", en La ley penal: revista de derecho penal, procesal y penitenciario, $\mathrm{N}^{\circ} 24,2006, \mathrm{pp} .14-36$

JAKOBS, G.: Sociedad, norma y persona en una teoría de un Derecho penal funcional, trad. M. Cancio Meliá y B. Feijóo Sánchez, Madrid, 2000

JAKOBS, G.: Sobre la normativización de la dogmática jurídico-penal, trad. Manuel Cancio Meliá y Bernardo Feijóo Sánchez, Madrid, 2003

JAKOBS, G. Y CANCIO MELIÀ, M., Derecho penal del enemigo, trad. M. Cancio Melià, Cizur Menor, 2006

JUANES PECES, A.: "Introducción a la responsabilidad penal de las personas jurídicas. Consideraciones generales y problemas sustantivos y procesales que dicha responsabilidad suscita", en Responsabilidad penal y procesal de las personas jurídicas, Memento experto, Madrid, 2015, pp. 7-20. 
LASCURAÍN SÁNCHEZ, J.A.: "Compliance, debido control y unos refrescos", en ARROYO ZAPATERO, L. y NIETO MARTÍN, A., El Derecho penal económico en la era compliance, Valencia, 2013, pp. 111-135

LESSIG, L.: Code 2.0, New York, 2006

MARTÍNEZ GARAY, L.: La imputabilidad penal. Concepto, fundamento, naturaleza jurídica y elementos, Valencia, 2005

DE LA MATA BARRANCO, N.J.: "Los protocolos de prevención de delitos en el ámbito empresarial: el referente de los modelos de organización y gestión de la regulación italiana", en PUENTE ABA, L.M. (ed.), Economía y Derecho penal en Europa: una comparación entre las experiencias italiana y española. Actas del Congreso hispano-italiano de Derecho penal económico. Universitá degli Studi di Milano, 29-30 de mayo de 2014, A Coruña, 2015, pp. 273-292. https://doi.org/10.17979/ spudc. 9788497497329.273

DE LA MATA BARRANCO, N.J.: "La exclusión de la responsabilidad penal de las personas jurídicas. Protocolos de prevención de delitos", en Responsabilidad penal y procesal de las personas jurídicas, Memento experto, Madrid, 2015, pp. 87-101

DE LA MATA BARRANCO, N.J., DOPICO GÓMEZ-ALLER, J., LASCURAIN SÁNCHEZ, J.A. y NIETO MARTÍN, A.: Derecho penal económico y de la empresa, Madrid, 2018 (disponible a texto completo en https:/e-archivo. uc3m.es/bitstream/handle/10016/26715/derecho_penal_ economico_2018.pdf? sequence $=6 \&$ isAllowed $=y$ )

DE LA MATA BARRANCO, N.J. y HERNÁNDEZ DÍAZ, L.: "Los problemas de congruencia en la concreción y aplicación de las sanciones previstas para las personas jurídicas", en DE LA CUESTA ARZAMENDI, J.L. (dir.) y DE LA MATA BARRANCO, N.J. (coord.), Responsabilidad Penal de las Personas Jurídicas, Cizur Menor, 2013, pp. 227-248 
MIR PUIG, S.: "Una tercera vía en materia de responsabilidad penal de las personas jurídicas", en Revista Electrónica de Ciencia Penal y Criminología, nº, 2004, pp. 1-17

MIR PUIG, S., Derecho penal. Parte general, Barcelona, 2007

MIRAS MARTÍN, N.: "El concepto de personas jurídicas penalmente responsables", en Anales de derecho, № 28, 2010, pp. 219-235

MUÑOZ CONDE, F. y GARCÍA ARÁN, M.: Derecho penal. Parte General, Valencia, 2015

PÉREZ MACHÍO, A.I.: La responsabilidad penal de las personas jurídicas, Granada, 2017

PÉREZ GONZÁLEZ, S.: "El bien jurídico penal desde una justificación ética", en Revista General de Derecho penal, $n^{\circ} 31,2019$, pp. 1-38

QUINTERO OLIVARES, G.: Parte General del Derecho Penal, Cizur Menor, 2010

RAMÓN RIBAS, E.: La persona jurídica en el derecho penal. Responsabilidad civil y criminal de la empresa, Granada, 2009.

RAMÓN RIBAS, E.: "De las consecuencias accesorias", en MORALES PRATS, F. y QUINTERO OLIVARES, G. (coords.), Comentarios al Código penal español, Cizur Menor, 2016, pp. 821-896

SILVA SÁNCHEZ, J.M.: "La aplicación judicial de las consecuencias accesorias para las empresas", en Indret: Revista para el Análisis del Derecho, №. 2, 2006, pp. 1-15

SILVA SÁNCHEZ, J.M.: "La evolución ideológica de la discusión sobre la responsabilidad penal de las personas jurídicas", en Revista de Derecho penal y criminología, 29, núm. 86-87, 2008, pp. 129-148

SILVA SÁNCHEZ, J.M.: “¿Adiós a un concepto unitario de injusto en la teoría del delito? A la vez, una breve contribución a la teoría de las medidas de seguridad", en Indret: Revista para el Análisis del Derecho, No. 3, 2014, pp. $1-21$ 
TIEDEMANN, K.: "Responsabilidad penal de las personas jurídicas", en Hurtado Pozo, J. (coord.), Responsabilidad penal de las personas jurídicas, Lima, 1997, pp. 97-126

WEBER, M.: La ética protestante y el espiritu del capitalismo, trad. J. Pérez, Madrid, (1905) 2015

ZUGALDÍA ESPINAR, J.M.: "La responsabilidad criminal de las personas jurídicas en el derecho penal español (Requisitos sustantivos y procesales para la imposición de las penas previstas en el art. 129 del Código Penal), en El nuevo Derecho Penal español. Estudios Penales en Memoria del Profesor José Manuel Valle Muñiz, coord. G. Quintero Olivares y F. Morales Prats, Cizur Menor, 2001, págs. 885-905

ZUGALDÍA ESPINAR, J.M.: "Societas delinquere potest: análisis de la reforma operada en el Código Penal español por la LO 5/2010, de 22 de junio", La ley penal: revista de derecho penal, procesal y penitenciario, n. 76, 2010, pp. 1-12

ZUGALDÍA ESPINAR, J.M.: "La responsabilidad criminal de las personas jurídicas, de los entes sin personalidad y de sus directivos: (análisis de los arts. 31 bis y 129 del Código Penal), Valencia, 2013.

ZUGALDÍA ESPINAR, J.M.: "La reforma del sistema de responsabilidad criminal de las personas jurídicas. Consideraciones críticas", Revista de la Facultad de Derecho de la Universidad de Granada, n. 16-18, 2013-2015, pp. 1509-1534

ZUGALDÍA ESPINAR, J.M.: "Modelos dogmático para exigir responsabilidad criminal a las personas jurídicas (a propósito de las SSTS de 2 de septiembre de 2015, 29 de febrero de 2016 y 16 de marzo de 2016)", La ley penal: revista de derecho penal, procesal y penitenciario, $\mathrm{n}$. 119, 2016, pp. 1-6

ZUGALDÍA ESPINAR, J.M.: "Teorías jurídicas del delito de las personas jurídicas (aportaciones doctrinales y jurisprudenciales). Especial consideración de la teoría del hecho de conexión)", Cuadernos de Política Criminal, n. 121, I, 2017, pp. 9-33 